\title{
Alcoholic fermentation of carbon sources in biomass hydrolysates by Saccharomyces cerevisiae: current status
}

\author{
Antonius J. A. van Maris · Derek A. Abbott · Eleonora Bellissimi · \\ Joost van den Brink · Marko Kuyper $\cdot$ Marijke A. H. Luttik • \\ H. Wouter Wisselink · W. Alexander Scheffers · Johannes P. van Dijken • \\ Jack T. Pronk
}

Received: 11 May 2006/ Accepted: 11 May 2006/Published online: 11 October 2006

(C) Springer Science+Business Media B.V. 2006

\begin{abstract}
Fuel ethanol production from plant biomass hydrolysates by Saccharomyces cerevisiae is of great economic and environmental significance. This paper reviews the current status with respect to alcoholic fermentation of the main plant biomass-derived monosaccharides by this yeast. Wild-type $S$. cerevisiae strains readily ferment glucose, mannose and fructose via the Embden-Meyerhof pathway of glycolysis, while galactose is fermented via the Leloir pathway. Construction of yeast strains that efficiently convert other potentially fermentable substrates in plant biomass hydrolysates into ethanol is a major challenge in metabolic engineering. The most abundant of these compounds is xylose. Recent metabolic and evolutionary engineering studies on $S$. cerevisiae strains that express a fungal xylose isomerase have enabled the rapid and efficient anaerobic fermentation of this pentose.
\end{abstract}

A. J. A. van Maris · D. A. Abbott · E. Bellissimi · J. van den Brink · M. Kuyper · M. A. H. Luttik · H. W. Wisselink · W. A. Scheffers · J. P. van Dijken · J. T. Pronk $(\bowtie)$

Department of Biotechnology, Delft University of Technology, Julianalaan 67, 2628 BC Delft The Netherlands e-mail: J.T.Pronk@TNW.TUDelft.NL

J. P. van Dijken

Bird Engineering B.V., Westfrankelandsedijk 1, 3115 HG Schiedam, The Netherlands
L-Arabinose fermentation, based on the expression of a prokaryotic pathway in $S$. cerevisiae, has also been established, but needs further optimization before it can be considered for industrial implementation. In addition to these already investigated strategies, possible approaches for metabolic engineering of galacturonic acid and rhamnose fermentation by $S$. cerevisiae are discussed. An emerging and major challenge is to achieve the rapid transition from proof-of-principle experiments under 'academic' conditions (synthetic media, single substrates or simple substrate mixtures, absence of toxic inhibitors) towards efficient conversion of complex industrial substrate mixtures that contain synergistically acting inhibitors.

Keywords Arabinose $\cdot$ Ethanol $\cdot$ Galacturonic acid $\cdot$ Hydrolysate $\cdot$ Rhamnose $\cdot$ Xylose

\section{Introduction}

Industrial and societal developments in the 20th century have to a large extent been shaped by petrochemistry. The ever increasing rate of exploration and exploitation of oil reserves has, for a long time, secured an abundant and cheap raw material for the production of bulk and fine chemicals as well as transport fuels. At the beginning of the 21st century, several factors are 
contributing in creating an urgent need for alternatives to an economy that predominantly depends on fossil resources.

In the past decade, the rate at which new fossil resources are discovered has ceased to match or exceed the global rate of oil consumption (Greene et al. 2002). As a result, it is clear that oil consumption cannot continue indefinitely at its current pace. This realization is strengthened by the fact that oil consumption worldwide continues to increase, amongst others due to rapid development of the major Asian economies (Bigg et al. 2003). While these factors already are leading to an increasing price of crude oil, geopolitical issues generate short- and long-term uncertainties that require national governments to reconsider their exclusive dependency on (often foreign) oil reserves (Klare 2001; Lugar and Woolsey 1999).

A fourth issue related to the use of fossil resources as feedstocks for chemical production ties in directly with global cycling of the elements, the central theme of this special issue of Antonie van Leeuwenhoek. At first glance, petrochemical production appears to be a cyclic process driven by solar energy (Fig. 1, left). However, the time constants of the processes in this cycle are alarmingly different. Formation of fossil resources is a process that takes aeons, while humanity is depleting the limited oil reserves in a period of, at best, a few centuries. One of the net results of this imbalance in the 'petrochemical carbon cycle' (Fig. 1, left) is a rapid increase of the carbon dioxide concentration in the Earth's atmosphere and oceans (Bigg et al. 2003). Since the beginning of the industrial revolution, the
$\mathrm{CO}_{2}$ concentration in the atmosphere has steadily increased, with a strong acceleration since the second half of the 20th century. There is strong and growing concern that increased $\mathrm{CO}_{2}$ levels affect the global climate via the well-publicized 'greenhouse effect' (Khandekar et al. 2005).

Plant biomass offers an attractive alternative, bypassing the need for fossil resources in chemical production and balancing the time constants of feedstock production and carbon dioxide fixation (Fig. 1, right). Transport fuels are a major product of the petrochemical industry. It would therefore be extremely attractive to have costeffective, sustainable means of producing transport fuels from plant biomass. One of the most promising processes in this respect is the production of fuel ethanol. Ethanol can be blended with conventional fuels or used as such. Depending on the mixture used, modifications to conventional car motors are either limited or not required (Iogen Corporation 2005).

The concept of producing fuel ethanol from plant biomass is by no means new. In 1918, the British Government appointed an Alcohol Motor Fuel Committee that, among other tasks, was charged with investigating the infrastructural implications of a large expansion of industrial ethanol production (Holden et al. 1919). A few years later, a famous predecessor of Gijs Kuenen at the Delft University of Technology, Albert Jan Kluyver, remarked in his inaugural address: 'The intensification of agriculture, and its development along lines of modern industry will thus, in the future, become more and more the order of the day. This will mean that the chemical industry will
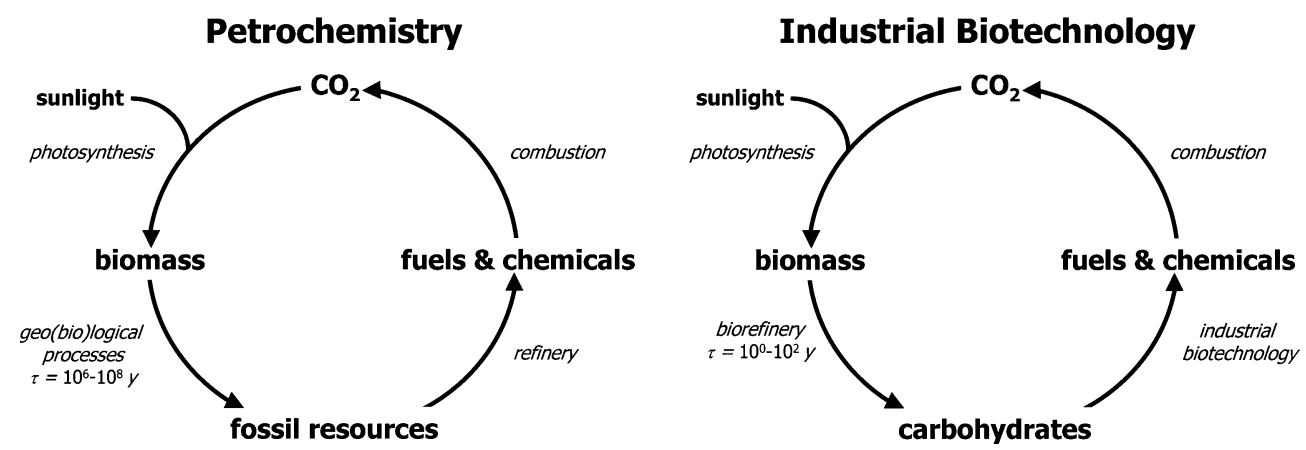

Fig. 1 The carbon cycle applied to consumer goods and fuels. Left: Petrochemical material streams. Right: Industrial biotechnological material streams 
be provided primarily with a few staple agricultural products whose value derives largely from their content of one or more of the three major groups of substances, the carbohydrates, oils and proteins. Particularly the carbohydrates-the sugars, starches and cell wall constituents-will become prominent as raw materials' (Kamp et al. 1959).

In the past decades consensus has been reached that, in the long run, sustainable and cost-effective production of ethanol from plant biomass should not only be based on the readily fermentable starch and sucrose fractions of plant carbohydrates, but also on the much more resistant lignocellulosic fractions. Again, this conclusion is hardly novel. Kressmann (1922) already stated: 'If the manufacturing cost of producing ethyl alcohol from wood can be reduced to the same figure or nearly the same figure as that for making it from grain or molasses, there will be a large margin in favour of producing the alcohol from wood waste'.

An important factor for the cost-effective production of ethanol from lignocellulosic feedstocks is the high-yield, high-rate fermentation of biomass hydrolysates to ethanol. The demands on the microorganisms that perform this reaction are more complicated than those for conventional ethanol production from hexoses or their disaccharides, which uses exclusively Saccharomyces yeasts. For example, hydrolysis of hemicellulose generates substantial amounts of pentose (C5) sugars that cannot be fermented by wild-type Saccharomyces cerevisiae. Additionally, plant hydrolysates contain numerous compounds that inhibit microbial growth (Klinke et al. 2004). Tolerance to these compounds, as well as to high concentrations of ethanol, is a prerequisite for efficient fermentation of biomass hydrolysates. Another important issue is the ability to grow under strictly anaerobic conditions. For example, many yeasts that ferment sugars (including pentoses) to ethanol, only do so when small amounts of oxygen are provided, while overaeration leads to increased respiration and suboptimal ethanol yields. Accurate dosage of oxygen in large-scale processes with viscous two-phase feedstocks is not only economically undesired, but also virtually impossible, thus underlining the importance of the ability for strict anaerobic growth such as exhibited by $S$. cerevisiae (Andreasen and Stier 1953, 1954; Visser et al. 1990).

The scale of industrial ethanol production is such that it is almost impossible to maintain aseptic conditions. Contaminations can result in reduction of the ethanol yield and formation of inhibitory compounds. Consequently, the process should be operated under conditions that minimize the risk of contamination. In general, the combined use of low $\mathrm{pH}$ and high ethanol concentrations suffices to keep contaminations at bay in large-scale yeast-based ethanol production processes. Although impressive results have been realized with respect to metabolic engineering of Escherichia coli and Zymomonas mobilis for ethanol production from non-glucose sugars (Dien et al. 2003), their low tolerance to acid, ethanol and other inhibitors will make it difficult to avoid contamination with, for example, lactic acid bacteria (Thomas et al. 2001). Another challenge in bacterial systems is the potential contamination with bacteriophages. An additional future option may be based on thermophilic cellulolytic Clostridia (Demain et al. 2005; Lynd et al. 2002). Although considerable progress has been made with respect to genetic engineering of these bacteria for homoethanolic fermentation, industrial implementation is not yet within reach.

Based on its widespread, large-scale application for bioethanol production from C6-substrates, $S$. cerevisiae appears to be the most promising metabolic-engineering platform for bioethanol production from plant hydrolysates. The most important challenge in this respect is the expansion of the narrow range of fermentable sugars. Wild-type $S$. cerevisiae strains readily ferment glucose, mannose and fructose as well as the disaccharides sucrose and maltose via the Emden-Meyerhof pathway of glycolysis, while D-galactose is fermented via combined action of the Leloir pathway and glycolysis. Production of ethanol from other carbon sources in plant hydrolysates (D-xylose, L-arabinose, galacturonic acid and L-rhamnose) requires extensive metabolic engineering. The aim of this review is to give an update of the current status of research on this subject and to outline the challenges in the 
conversion of $S$. cerevisiae into a biomass hydrolysate-fermenting organism.

\section{Composition of biomass hydrolysates}

Lignocellulosic biomass

There are a wide variety of potential feedstocks for fuel ethanol production. Fast-growing trees, grass, whole plants, industrial by-products, aquatic plants, waste products (including agricultural, paper industry and forestry waste), municipal and industrial waste streams, all represent examples of plant-derived lignocellulosic resources (Aristidou and Penttilä 2000; Galbe and Zacchi 2002; Howard et al. 2003; Lee 1997; Zaldivar et al. 2001). The nature and availability of lignocellulosic feedstocks in different parts of the world depends on climate and other environmental factors, agricultural practice and technological development (Claassen et al. 1999). Lignocellulose consists of an intermeshed and chemically bonded complex of three main polymers (Table 1): cellulose, hemicellulose, lignin and depending on the feedstock, pectin (HahnHägerdal et al. 1991; Ingram et al. 1999; Perez et al. 2002; Zaldivar et al. 2001).

Cellulose, the major constituent of lignocellulose (Table 1), is a linear polymer composed of thousands of D-glucose subunits linked by $\beta$-(1$4)$-glycosidic bonds. Linear cellulose typically occurs as parallel polymers with extensive hydrogen bonding (Lynd 1996). This structural conformation, as well as the close association with lignin, hemicellulose, starch, protein and minerals makes cellulose highly resistant to hydrolysis

Table 1 Polymer composition of lignocellulose (data from Ingram et al. 1999)

\begin{tabular}{lll}
\hline Fraction & $\begin{array}{l}\text { Content in } \\
\text { lignocellulose }\end{array}$ & $\begin{array}{l}\text { Major } \\
\text { monomers }\end{array}$ \\
\hline $\begin{array}{l}\text { Cellulose } \\
\text { Hemicellulose }\end{array}$ & $\begin{array}{l}33-51 \% \\
19-34 \%\end{array}$ & $\begin{array}{l}\text { Glucose } \\
\text { Glucose, mannose, } \\
\text { galactose, xylose } \\
\text { and arabinose }\end{array}$ \\
$\begin{array}{l}\text { Lignin } \\
\text { Pectin }\end{array}$ & $20-30 \%$ & $\begin{array}{c}\text { Aromatic alcohols } \\
\text { Galacturonic acid } \\
\text { and rhamnose }\end{array}$ \\
\hline
\end{tabular}

(Aristidou and Penttilä 2000; Klinke et al. 2004; Perez et al. 2002; Zaldivar et al. 2001).

Hemicellulose, the second major constituent of lignocellulose (Table 1) is a highly branched and complex heteropolymer that contains hexoses (D-glucose, D-galactose, D-mannose, L-rhamnose, L-fucose), pentoses (D-xylose and L-arabinose) and uronic acids (D-glucuronic acid and D-galacturonic acid). Hemicellulose composition is strongly dependent on the plant source. However, in contrast to cellulose, hemicellulose is easily hydrolyzed to its constituent monosaccharides (Aristidou and Penttilä 2000; Klinke et al. 2004; Perez et al. 2002; Zaldivar et al. 2001).

Lignin, constituting $10-20 \%$ of biomass dry weight (Table 1), is an aromatic polymer containing phenolic residues such as trans- $\rho$ coumaryl alcohol, trans- $\rho$-coniferyl alcohol and trans- $\rho$-sinapyl alcohol (Hahn-Hägerdal et al. 1991; Ingram et al. 1999; Klinke et al. 2004; Perez et al. 2002; Zaldivar et al. 2001). While the lignin fraction does not contribute fermentable carbon sources, it is relevant as a potential source of microbial inhibitors (see below).

Although, in 'average' plant biomass, pectin is less prominent than cellulose and hemicellulose, some agricultural waste streams such as citrus peels and sugar beet pulp are extremely rich in pectin (Doran et al. 2000; Doran and Foster 2000; Grohmann et al. 1998; Grohmann and Bothast 1994). Pectins are complex and heterogeneous polymers that primarily act as hydrating and cementing agents for the cellulosic matrix of plant cell walls. The principal unit in pectin chains is $\alpha-(1-4)$ linked galacturonic acid. The galacturonic acid residues can be esterified with methyl and acetyl groups (Baciu and Jördening 2004; Oosterveld 1997; Thakur et al. 1997). Additionally, pectin contains the branched polysaccharides rhamnogalacturonan I, rhamnogalacturonan II and xylogalacturonan (Micard et al. 1996; Oosterveld 1997; Zandleven et al. 2005).

\section{Pretreatment and hydrolysis}

Conversion of lignocellulosic materials to fermentable sugars is an intensive process that involves a combination of pretreatment (chemical and mechanical) and hydrolysis (chemical and 
enzymatic) (Galbe and Zacchi 2002). Pretreatment is required to increase the surface area of the feedstock, thereby rendering the lignocellulose accessible for hydrolysis (Klinke et al. 2004). Pretreatment methods include concentrated- or dilute-acid treatment, high-pressure steam explosion, ammonia-freeze explosion and wet oxidation (Galbe and Zacchi 2002; Klinke et al. 2004). These methods are most often used in combination, such as in the commonly used combination of dilute-acid hydrolysis $(0.5-1.0 \%$ sulfuric acid) with high-pressure steam explosion. During this pre-treatment, hemicellulose is readily chemically hydrolyzed, while cellulose is essentially inert (Galbe and Zacchi 2002). Pretreatment of hemicellulose results in the release of monomeric sugars and in the production of a complex mixture of compounds that inhibit the bioconversion of these sugars (Ingram et al. 1999; Klinke et al. 2004; Mussatto and Roberto 2004). It has been proposed that the lignin fraction, which can be separated after pretreatment, may be used as an ash-free, solid fuel for the generation of heat and/or electricity (Galbe and Zacchi 2002).

Cellulose hydrolysis can either be done chemically or enzymatically using specific cellulolytic enzymes. Although chemical processes are more technically mature, they generally have greater environmental and personnel risks (Lynd 1996). Until recently, the cost of cellulosehydrolyzing enzymes was prohibitive for commercial ethanol production from lignocellulosic biomass. However, over the past five years enormous progress has been made in the development of novel hydrolytic enzymes, amongst others in research efforts at Novozymes and Genencor that were subsidized by the USA National Renewable Energy Laboratories (http://www.nrel.gov). While further optimization of these enzymes and their integration with physical/chemical techniques for sugar release is needed, there appear to be no insurmountable barriers for their industrial implementation. For more information on naturally produced cellulases, such as for instance by the wood-rotting fungus Trichoderma reesei, we refer to Galbe and Zacchi (2002), Howard et al. (2003) and Perez et al. (2002). During enzymatic hydrolysis incomplete conversion of the cellulose and buildup of cellobiose can occur due to inhibition by the end products. This can, for instance, be avoided by simultaneous hydrolysis and fermentation. For comparison of separate or simultaneous hydrolysis and fermentation we refer to excellent papers by Lynd (1996), Galbe and Zacchi (2002) and Ingram et al. (1999). In practice, it may not be necessary to completely hydrolyse polymers to monosaccharides. Wildtype $S$. cerevisiae strains readily ferment the disaccharides sucrose and maltose, and the ability to hydrolyse cellobiose, lactose and melibiose has been introduced by metabolic engineering and/or classical strain improvement (Domingues et al. 1999a, b; Ronnow et al. 1999; van Rooyen et al. 2005; Vincent et al. 1999).

Pectin hydrolysis can be accomplished by a mixture of enzymes, consisting of pectin methyl esterase, pectin acetyl esterase, endo-polygalacturonase, endo-pectin lyase, rhamnogalacturonan hydrolyase, rhamnogalacturonan lyase, rhamnogalacturonan acetyl esterase, arabinofuranosidase, endo-arabinose, endo-galactanase and $\beta$-galactosidase (Baciu and Jördening 2004; Oosterveld 1997). While enzyme costs are still an important issue, the recent developments in cellulose hydrolysis suggest that future cost-effective production of pectinolytic enzymes is feasible.

Monosaccharides in biomass hydrolysates

Depending on the feedstock, the resulting hydrolysates contain a large variety of sugars (Table 2). It is clear that glucose and xylose are often the predominant sugars. However, for economically efficient conversion to commodity chemicals like ethanol, the profit margins are small. This creates an incentive to also convert smaller carbohydrate fractions, such as arabinose, galacturonic acid and rhamnose, to ethanol. Conversion of such other sugars becomes even more important when side streams of existing processes that are enriched for these compounds are used to produce ethanol. In the following paragraphs, an overview will be presented of the current status of the utilization of these various sugars by $S$. cerevisiae. In addition, we will briefly address the challenges posed by the complex mixture of inhibitory 
Table 2 Composition (major sugars) of common agricultural lignocellulosic feedstocks (adapted from Grohmann and Bothast 1994; Lee 1997; http://www.ecn.nl/phyllis/)

\begin{tabular}{|c|c|c|c|c|c|c|}
\hline & Corn stover & Wheat straw & Bagasse & Cotton gin & Sugar beet pulp & Switch grass \\
\hline \multicolumn{7}{|c|}{ Carbohydrate (\%) } \\
\hline Glucose & 34.6 & 32.6 & 39.0 & 37.1 & 24.1 & 31.0 \\
\hline Mannose & 0.4 & 0.3 & 0.4 & 1.1 & 4.6 & 0.2 \\
\hline Galactose & 1.0 & 0.8 & 0.5 & 2.4 & 0.9 & 0.9 \\
\hline Xylose & 19.3 & 19.2 & 22.1 & 9.4 & 18.2 & 0.4 \\
\hline Arabinose & 2.5 & 2.4 & 2.1 & 2.3 & 1.5 & 2.8 \\
\hline Uronic acids & 3.2 & 2.2 & 2.2 & NA & 20.7 & 1.2 \\
\hline \multicolumn{7}{|c|}{ Non-carbohydrate (\%) } \\
\hline Lignin & 17.7 & 16.9 & 23.1 & 28.8 & 1.5 & 17.6 \\
\hline Extractives & 7.7 & 13.0 & 3.8 & 7.7 & NA & 17.0 \\
\hline Ash & 10.4 & 10.2 & 3.7 & 10.5 & 8.2 & 5.8 \\
\hline
\end{tabular}

compounds that may originate during the preparation of hydrolysates (see below).

\section{Fermentation of hexoses by Saccharomyces cerevisiae}

Wild-type $S$. cerevisiae ferments glucose, the dominant sugar in all plant hydrolysates, at high rates even under anaerobic conditions. The anaerobic ethanol production rate in defined media is as high as $30 \mathrm{mmol} \mathrm{g}_{\text {biomass }}^{-1} \mathrm{~h}^{-1}$ at $30^{\circ} \mathrm{C}$ (Bakker et al. 2000). S. cerevisiae contains an elaborate system for hexose transport. The 32 members of the HXT (hexose transporter) family in $S$. cerevisiae differ with respect to transcriptional and posttranscriptional regulation, substrate specificity and affinity for glucose (Boles and Hollenberg 1997; Kruckeberg 1996). However, since they all transport glucose via facilitated diffusion, glucose uptake only requires a concentration gradient across the plasma membrane. After uptake, glucose dissimilation proceeds via the Embden-Meyerhof glycolytic pathway. This pathway oxidizes glucose to two pyruvate, resulting in the net formation of two ATP per glucose (Fig. 2). In anaerobic, fermentative cultures of $S$. cerevisiae, the NADH formed by glyceraldehyde-3-phosphate dehydrogenase is reoxidized via alcoholic fermentation. This essential redox balancing involves the combined activity of pyruvate decarboxylase and alcohol dehydrogenase. But obviously glucose is not the only carbohydrate present in the hydrolysates. In order to ferment such non-glucose carbohydrates with $S$. cerevisiae, three key criteria have to be met: (i) presence of a functional transporter in the plasma membrane, (ii) presence of enzyme(s) that couple metabolism of the carbohydrate to the main glycolytic pathway and (iii) maintenance of a closed redox balance.

Mannose and fructose are two isomers of glucose that occur in all plant-derived biomass hydrolysates and that can be fermented by all wild-type $S$. cerevisiae strains. The general observation that yeast capable of fermenting glucose can also ferment fructose and mannose, is known as the Kluyver rule (Kluyver 1914). Both mannose and fructose are transported by all the different members of the HXT family, although the $K_{m}$ value is generally higher than that for glucose (Reifenberger et al. 1997). After phosphorylation by hexokinase, mannose-6-phosphate is isomerized to fructose-6-phosphate by phosphomannose isomerase, encoded by the PMI40 gene. Hexokinase is also responsible for phosphorylation of fructose to fructose-6-phosphate, which is subsequently metabolized through glycolysis. As mannose and glucose compete for the same hexose transporters, kinetics of mixed-substrate utilization is determined by their relative and absolute concentrations in hydrolysates.

Galactose, another sugar that can be fermented by $S$. cerevisiae, is first taken up by a dedicated member of the $H X T$ family, the galactose permease Gal2p, and subsequently converted into glucose-6-phosphate via the Leloir pathway (Leloir 1951; Melcher 1997) 


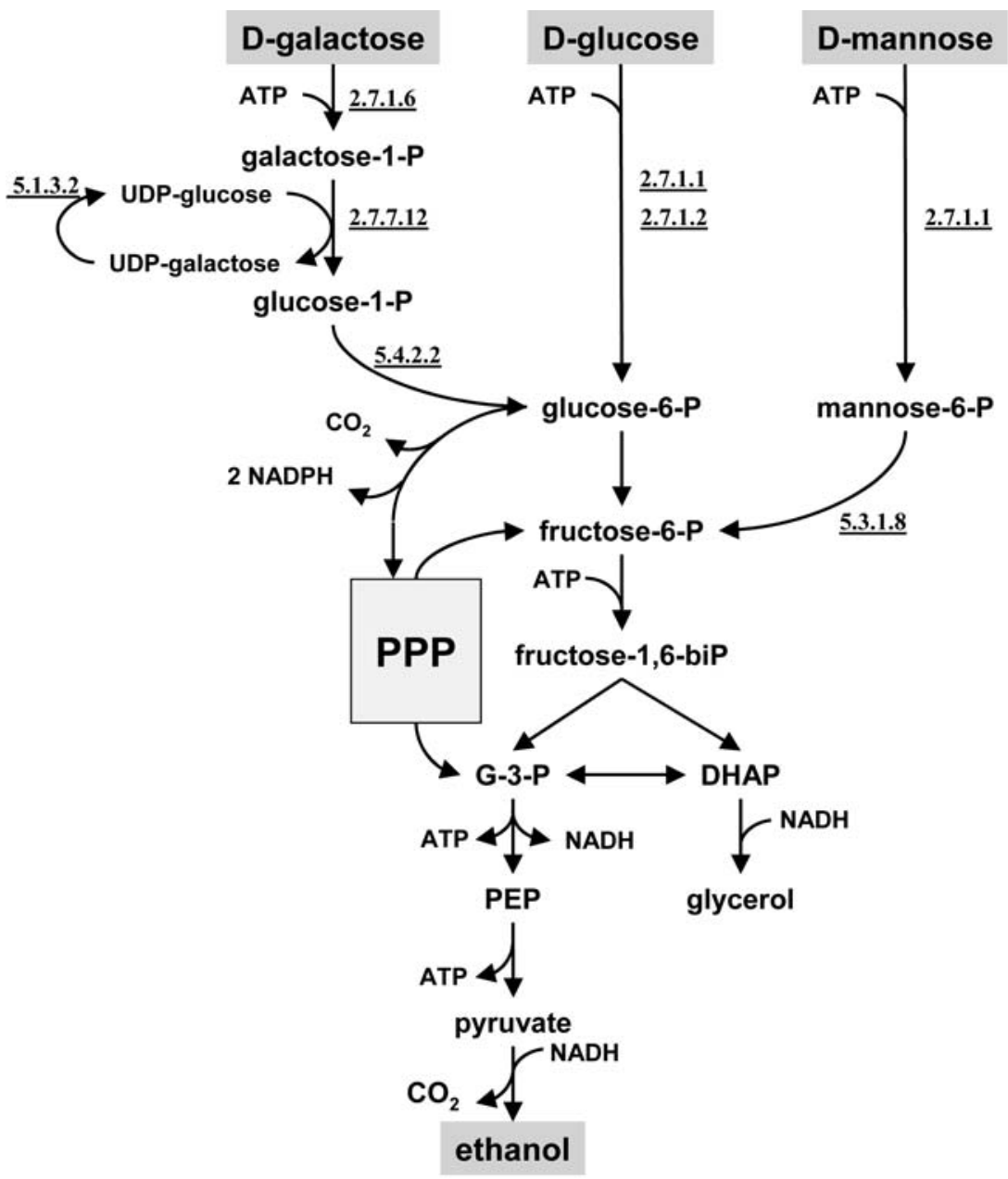

Fig. 2 Hexose catabolism of Saccharomyces cerevisiae. Underlined EC numbers represent enzymes/steps present in $S$. cerevisiae metabolism. The gene names encoding the various enzymes are given in parentheses in the legend of this figure. Glucose catabolism: 2.7.1.1, hexokinase (HXK1/HXK2); 2.7.1.2, glucokinase (GLK1); Galactose catabolism: via the Leloir pathway: 2.7.1.6, galactokinase $(G A L 1)$; 2.7.7.12, galactose-1-phosphate uridylyltransfer-

(Fig. 2). This pathway, which links galactose catabolism to the main glycolytic pathway, consists of three reactions. After phosphorylation of galactose by galactokinase (Gal1p), galactose1-phosphate uridylyltransferase (Gal7p) converts UDP-glucose and galactose-1-phosphate to UDP-galactose and glucose-1-phosphate. UDPgalactose is reconverted into UDP-glucose by the uridine-diphosphoglucose 4-epimerase (Gal10p, Douglas and Hawthorne 1964). Finally, glucose-1-phosphate is converted to ase (GAL7); 5.1.3.2, UDP-glucose 4-epimerase (GAL10); 5.4.2.2 phosphoglucomutase (GAL5/PGM2). Mannose catabolism: 2.7.1.1, hexokinase I (HXK1); 5.3.1.8, mannose-6-phosphate isomerase (PMI40). G-3-P, Glyceraldehyde-3-phosphate; DHAP, dihydroxy-acetone-phosphate; PEP, phospho-enol pyruvate; PPP, Pentose phosphate pathway

glucose-6-phosphate by phosphoglucomutase, major and minor isoforms of which are encoded by PGM2 (also called GAL5) and PGM1, respectively (Fig. 2) (Johnston et al. 1987; Oh and Hopper 1990). In wild-type S. cerevisiae strains, growth rates on galactose are generally lower than those on glucose. Bro et al. (2005) have recently demonstrated that overexpression of $P G M 2$ caused a $70 \%$ increase of galactose consumption rates in aerobic batch cultures. It has not yet been investigated whether a similar 
positive effect can be reached under anaerobic, fermentative growth conditions.

Expression and activity of the Leloir pathway in $S$. cerevisiae is positively controlled by galactose. Galactose induction of the GAL genes is initiated by ATP-dependent interaction of galactose with Gal3p, which then forms a complex with the negative regulator Gal80p (Platt and Reece 1998). This releases the positive transcriptional regulator Gal4p from Gal80p control and allows it to activate transcription of the GAL1, GAL2, GAL7 and GAL10 genes that contain the upstream activation sequences $\left(\mathrm{UAS}_{\mathrm{GAL}}\right)$ in their promoter regions (Leuther and Johnston 1992; Wu et al. 1996). Presence of glucose causes a virtually complete transcriptional repression of the $G A L$ genes and thereby effectively shuts down galactose metabolism (Johnston et al. 1994). This repression is mediated by Mig1p, the nonphosphorylated form of which binds to upstream repression sequences $\left(\mathrm{URS}_{\mathrm{GAL}}\right)$ found in several of the GAL genes, including the transcriptional activator Gal4p (Nehlin et al. 1991). Additionally, Gal6p has been proposed to control degradation of the GAL transcripts (Ostergaard et al. 2001). Besides transcriptional regulation by glucose, the Gal2p permease is subject to glucose catabolite inactivation (Horak and Wolf 1997).

The glucose concentration in plant hydrolysates will generally lead to complete repression of galactose metabolism, thus preventing simultaneous consumption of glucose and galactose. Whereas fast, sequential utilization of different carbohydrates is not necessarily a problem in industrial ethanol production, the long lag phase that separates glucose and galactose consumption in mixed-substrate cultures of wild-type $S$. cerevisiae strains is a problem that needs to be addressed. Interestingly, a natural isolate of S. ccerevisiae has recently been reported to prefer galactose over glucose (Keating et al. 2004). Moreover, Ostergaard et al. (2001) have demonstrated that combined deletion of GAL6, GAL80 and MIG1 in a laboratory $S$. cerevisiae strain led to a partial co-consumption of glucose and galactose in aerobic batch cultures. This indicates that metabolic engineering can contribute to improved kinetics of mixed-substrate utilization.

\section{Xylose fermentation}

In plant biomass hydrolysates, the pentose sugar xylose ('wood sugar') is the major monosaccharide that cannot be fermented by wild-type strains of $S$. cerevisiae. Although $S$. cerevisiae can neither ferment nor assimilate xylose, this is not a general characteristic of yeasts. The earliest observations on xylose fermentation by yeasts stem from the early 1980's. Yeasts like Pachysolen tannophilus (Slininger et al. 1982) and Candida tropicalis (Gong et al. 1981a) are able to ferment xylose to ethanol. In an extensive screening of 200 yeast strains able to grow on xylose, nineteen were found that produced $0.1-1.0 \mathrm{~g} \mathrm{l}^{-1}$ of ethanol under fermentative conditions from $20 \mathrm{~g} \mathrm{l}^{-1} \mathrm{xy}$ lose. Strains from the species Brettanomyces naardenensis, Candida shehatae, Candida tenuis, $P a$. tannophilus, Pichia segobiensis and Pichia stipitis produced more than $1.0 \mathrm{~g} \mathrm{l}^{-1}$ (Toivola et al. 1984). Since xylose is a significant constituent of plant biomass it is not surprising that all these yeasts originate from plant-related sources.

Surprisingly, only a small number of facultatively fermentative yeasts that can metabolise xylose are able to ferment this sugar to ethanol. This apparent discrepancy is intrinsic to the metabolic pathway of xylose metabolism. This pathway, as first described in 1955 (Gunsalus et al. 1955) links xylose metabolism to the pentose-phosphate pathway by converting xylose into xylulose 5-phosphate (Fig. 3). In xylose-fermenting yeasts, two oxidoreductases are involved in this process, xylose reductase (XR) and xylitol dehydrogenase $(\mathrm{XDH})$. As these oxidoreductases have different cofactor specificities, conversion of xylose into xylulose yields one $\mathrm{NADP}^{+}$and one NADH. $\mathrm{NADPH}$ and $\mathrm{NAD}^{+}$need to be regenerated in order to maintain redox balance. For NADPH this can be accomplished by diverting part of the fructose-6-phosphate produced into the oxidative part of the pentose-phosphate pathway. Under aerobic conditions the NADH can be reoxidized via the respiratory chain with molecular oxygen. However, under anaerobic conditions another electron 


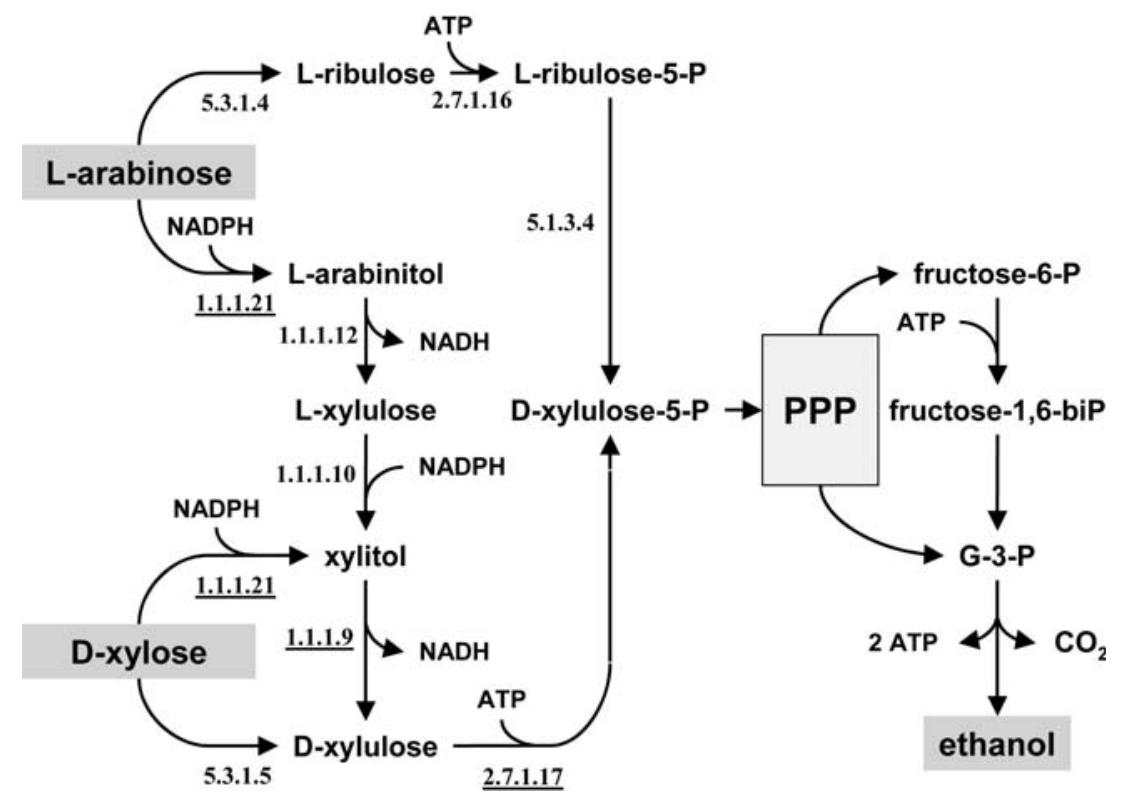

Fig. 3 D-Xylose and L-arabinose catabolism in metabolically engineered $S$. cerevisiae strains. Underlined EC numbers represent enzymes/steps present in 'wild-type' $S$. cerevisiae metabolism. The gene names corresponding to the enzymes are given in parentheses in the legend of this figure. 1.1.1.21, aldose/xylose reductase (GRE3/xyl1); 1.1.1.9, xylitol dehydrogenase ( $X Y L 2 / x y l 2) ; 2.7 .1 .17$, xylu-

acceptor is required to reoxidise the NADH, like acetoin (Scheffers 1966; Bruinenberg et al. 1983a) or furfural (Wahlbom and Hahn-Hägerdal 2002). If no such electron acceptor is available, the cell cannot maintain redox balance and will not ferment xylose under anaerobic conditions. A second solution to this redox imbalance would be to convert NADH into NADPH with a transhydrogenase. However, no such enzymes have been discovered in yeasts (Blank et al. 2005; Bruinenberg et al. 1983b) and introduction of a heterologous transhydrogenase in $S$. cerevisiae has demonstrated that in vivo conditions favour NADPH production (Nissen et al. 2001).

Why is it then that some yeasts such as Pichia stipitis and Pachysolen tannophilus are able to ferment xylose under anaerobic conditions? The answer is in the properties of the xylose reductase enzyme. In Table 3 the cofactor dependence of xylose reductase activity in several yeast strains is listed, thus revealing a clear correlation between the ability of their XR to utilise both NADH and $\mathrm{NADPH}$ and their ability to anaerobically lokinase $(X K S 1 / x y l 3) ; 5.3 .1 .5$, xylose isomerase $(x y l A)$; 1.1.1.12, arabinitol 4-dehydrogenase (lad1); 1.1.1.10, Lxylulose reductase $(l x r 1) ; 5.3 .1 .4$, L-arabinose isomerase $(\operatorname{ara} A) ; 2.7 .1 .16$, L-ribulokinase $(\operatorname{araB}) ; 5.1 .3 .4$, L-ribulose5-phosphate 4-epimerase ( $a r a D)$. G-3-P, glyceraldehyde-3phosphate; PPP, pentose phosphate pathway

ferment xylose. This relationship was clearly established for Pa. tannophilus and Pi. stipitis (see Table 4, and Bruinenberg et al. 1984). The inherent drawback of this dual specificity $\mathrm{XR}$ is the production of xylitol. For every NADH that is reoxidized by XR one xylitol is produced as byproduct. In Fig. 4 the theoretical yields of ethanol, xylitol and glycerol are given as a function of the ratio of in vivo fluxes through NADPH- and NADH-linked xylose reductase. The relations of these yields are derived from the following equations (Kuyper et al. 2004), assuming anaerobic conditions and formation of glycerol not taking place at ratios lower than 1 .

$$
\begin{aligned}
& \text { Ratio }=0: 6 \text { xylose } \rightarrow 10 \text { ethanol }+10 \mathrm{CO}_{2} \\
& +10 \text { ATP } \\
& \text { Ratio }=1: 12 \text { xylose } \rightarrow 9 \text { ethanol }+12 \mathrm{CO}_{2} \\
& +9 \text { ATP }+6 \text { xylitol } \\
& \text { Ratio }=\infty: 6 \text { xylose }+3 \text { ATP } \rightarrow 3 \text { ethanol } \\
& +6 \text { glycerol }+6 \mathrm{CO}_{2}
\end{aligned}
$$


Table 3 NADPH-linked and NADH-linked xylose reductase activities in batch cultures of various D-xyloseassimilating yeasts

\begin{tabular}{|c|c|c|c|c|c|}
\hline \multirow[t]{2}{*}{ Organism } & \multirow[t]{2}{*}{ CBS no. } & \multicolumn{3}{|c|}{ Spec. act. } & \multirow{2}{*}{$\begin{array}{l}\text { Xylose } \\
\text { fermentation }\end{array}$} \\
\hline & & NAD & NA & Ratio & \\
\hline \multirow{8}{*}{$\begin{array}{c}\text { Candida } \\
\text { tenuis }\end{array}$} & 615 & 2 & 130 & 0.02 & - \\
\hline & 2226 & 7 & 320 & 0.02 & - \\
\hline & 2885 & $0^{\mathrm{b}}$ & 100 & 0 & - \\
\hline & 4113 & 60 & 120 & 0.5 & + \\
\hline & 4285 & 305 & 670 & 0.5 & + \\
\hline & 4434 & $0^{\mathrm{b}}$ & 485 & 0 & - \\
\hline & 4435 & 340 & 670 & 0.5 & + \\
\hline & 4604 & $0^{\mathrm{b}}$ & 365 & 0 & - \\
\hline $\begin{array}{l}\text { Candida } \\
\text { shehatae }\end{array}$ & 5813 & 210 & 480 & 0.4 & + \\
\hline $\begin{array}{c}\text { Candida } \\
\text { utilis }\end{array}$ & 621 & $0^{\mathrm{b}}$ & 75 & 0 & - \\
\hline
\end{tabular}

Cells were harvested at mid-exponential growth phase. Enzyme activities are expressed as nmol $\mathrm{min}^{-1} \mathrm{mg}$ prot. ${ }^{-1}$. Data taken from Bruinenberg et al. (1984)

a Results obtained in a fermentation test using a Durham vial: -: no gas production, ethanol less than $0.3 \mathrm{~g} \mathrm{l}^{-1} ;+$ : gas production, ethanol higher than $5.0 \mathrm{~g} \mathrm{l}^{-1}$

b not detectable

When the NADPH/NADH ratio equals zero, only NADH-linked reduction of xylose takes place and all xylose can be converted to ethanol because the conversion of xylose into xylulose is redox neutral (Eq. 1). At a ratio of one, one xylose must be converted with NADH-linked XR for every xylose converted with NADPH-linked $\mathrm{XR}$ (Eq. 2). With a ratio that is infinite, there is no NADH-linked XR activity and the excess $\mathrm{NADH}$ can only be reoxidized through the production of glycerol (Eq. 3). Since this equation

Table 4 Activities of xylose reductase and rate of ethanol production from xylose-batch cultures switched to anaerobic conditions

\begin{tabular}{lccc}
\hline & C. utilis & Pa. tannophilus & Pi. stipitis \\
\hline qethanol & 0 & 8 & 54 \\
Xylose reductase & & \\
NADH & 0 & 9 & 310 \\
NADPH & 75 & 220 & 600 \\
Ratio & 0 & 0.04 & 0.5 \\
\hline
\end{tabular}

$\overline{q_{\text {ethanol }} \text { is expressed as } \mathrm{mg} \text { ethanol } \mathrm{g} \text { cells }{ }^{-1} \mathrm{~h}^{-1} \text {. Enzyme }}$ activities were determined in cells harvested just prior to the shift from aerobic to anaerobic conditions and are expressed as nmol $\mathrm{min}^{-1} \mathrm{mg}$ protein ${ }^{-1}$. Data taken from Bruinenberg et al. (1984)

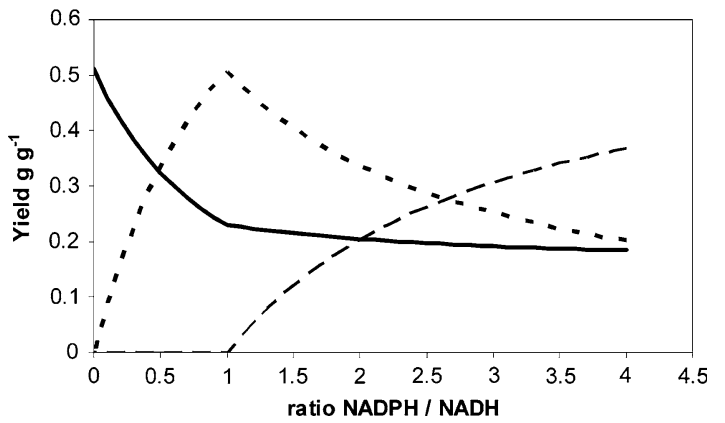

Fig. 4 Calculated ethanol (-), xylitol (- - ) and glycerol $(--)$ yields during anaerobic catabolism of xylose as a function of the ratio of the fluxes via NADPH-linked and NADH-linked xylose reductase calculated from equations $1,2,3$. Assumed is that glycerol formation does not occur below a ratio of 1 , in other words: NADH is preferentially shuttled into xylitol formation instead of glycerol formation. Above a ratio of 1 there is a stoichiometric necessity for an alternative redox sink such as glycerol formation. At a ratio of 4.0 the ATP yield is zero

requires energy input, glycerol formation cannot solve the redox problem of the XR-XDH system.

Since $S$. cerevisiae is capable of metabolizing xylulose, albeit at very low rates (Hsiao et al. 1982; Wang and Schneider 1980), the first challenge in realizing efficient alcoholic fermentation of xylose by this yeast was the introduction of (a) heterologous enzyme(s) that convert xylose into xylulose, without causing cofactor imbalances. To quote the work of Bruinenberg et al. (1983a): 'Efficient anaerobic fermentation of xylose to ethanol by yeasts apparently requires that the first two reactions of its metabolism be circumvented. Implantation of a xylose isomerase would offer a possibility. ... another option would be to select for a yeast possessing a xylose reductase and a xylitol dehydrogenase which are linked to the same coenzyme system, thus eliminating the production of excess NADH in the process of ethanol production.'

Both postulated options have, to a certain extend, been realized since then. Petschacher et al. (2005) were able to shift the cofactor preference of the xylose reductase of Candida tenuis from NADPH towards NADH by site-directed mutagenesis. Regrettably, this paper does not mention the xylose fermentation properties of the strains expressing the engineered enzyme. The introduction of a xylose isomerase (E.C. 5.3.1.5) in $S$. cerevisiae has been tried many times with 
disappointing results (Blow et al. 1990; Fukazawa 1989; Gárdonyi and Hahn-Hägerdal 2003; Ho et al. 1984; Moes et al. 1996; Sarthy et al. 1987; Walfridsson et al. 1996). The lack of success of these heterologous expressions has been attributed to improper protein folding, posttranslational modifications, disulfide-bridge formation, and the internal $\mathrm{pH}$ of yeast. A notable exception in this line of research was the xylose isomerase from Thermus thermophilus (Walfridsson et al. 1996). This was the first xylose isomerase that was functionally expressed in S. cerevisiae. However, the enzyme activity of the isomerase at temperatures allowing yeast growth was not high enough to facilitate efficient xylose fermentation. Even when all enzymes involved in the conversion of xylulose to glycolysis intermediates were overexpressed the xylose isomerase activity $\left(0.017 \mathrm{U} \mathrm{mg}^{-1}\right)$ was too low for efficient xylose metabolism (Karhumaa et al. 2005).

Because of the disappointing results of the xylose isomerase research, a lot of attention has been given to the expression of the Pi. stipitis XR and $\mathrm{XDH}$ in $S$. cerevisiae (for an excellent review see Jeffries and Jin 2004). Contrary to the xylose isomerases from Archaea and Bacteria, these eukaryotic genes could be functionally expressed in Saccharomyces, enabling this yeast to metabolise xylose (Kötter et al. 1990; Kötter and Ciriacy 1993). However, anaerobic xylose fermentation by engineered strains was inevitably accompanied by considerable xylitol production. For every NADPH used by XR, one NADH needs to be reoxidized, and the only way for these yeasts to do so is to produce xylitol. Table 5 presents ethanol and xylitol yields for different Saccharomyces strains engineered for xylose metabolism via the heterologous expression of XR and XDH. In this Table, three strains stand out in having both a low xylitol yield and a high ethanol yield. Strain TMB 3255 (Jeppsson et al. 2002) has a very low specific xylose consumption rate and will not be further discussed here. The other strains, 1400 (pLNH32) and 424A(LNH-ST), were constructed by Ho and co-workers at Purdue University and both have a reasonable ethanol yield and comparatively low xylitol production. The mechanism by which cofactor imbalances are prevented in these strains is unclear. A relevant factor in this respect may be the large variation in XR cofactor dependency observed in Candida tenuis (see Table 3): the Purdue strains express the xylose reductase gene from CBS 5773 (Chen and Ho 1993), whereas the TMB strains from Lund express that from CBS 6054 (Eliasson et al. 2000; Walfridsson et al. 1995). The cultivation method may also help to explain the low xylitol production found with the Purdue strains. As outlined above, anaerobic cultivation of $S$. cerevisiae strains expressing both $\mathrm{XR}$ and $\mathrm{XDH}$ on xylose is expected to lead to substantial production of xylitol, unless an electron acceptor is present. In their papers Ho and co-workers describe a cultivation method that applies oxygen limitation by covering shake flasks with Saran wrap. It is conceivable that this system allows for sufficient diffusion of oxygen into the system to regenerate $\mathrm{NAD}^{+}$via respiration instead of via xylitol production. On an industrial scale, this would require exact aeration of the reactors, which is too costly for a viable production process.

The recent discovery of the first fungal xylose isomerase (Harhangi et al. 2003) has been an important breakthrough in the field of xylose fermentation. This xylose isomerase from the obligately anaerobic fungus Piromyces sp.E2 was the first enzyme of its kind that could be functionally expressed in S. cerevisiae at high levels (Kuyper et al. 2003). The introduction of the XylA gene was sufficient to enable the laboratory strain CEN.PK113-7D to grow slowly on xylose as the sole carbon source under aerobic conditions (Table 6). Subsequently the XylA-expressing strain (RWB202) was subjected to evolutionary engineering, resulting in a strain (RWB 202-AFX) capable of anaerobic growth on xylose producing mainly ethanol, $\mathrm{CO}_{2}$, glycerol and biomass and notably little xylitol (Kuyper et al. 2004). RWB 202-AFX performed nearly identical to the wild type grown on glucose, with the exception of a slightly reduced specific growth rate.

The ethanol production rate of RWB 202-AFX was still too low to be considered for industrial applications. To obtain a higher specific rate of ethanol production, a strain was constructed that, in addition to the XylA gene, overexpressed all genes involved in the conversion of xylose into intermediates of glycolysis. This strain, RWB 217 , 
Table 5 Ethanol and xylitol yields of Saccharomyces yeast strains engineered for xylose utilization by introduction of heterologous xylose reductase and xylitol dehydrogenase genes

\begin{tabular}{|c|c|c|c|c|c|}
\hline \multirow[t]{2}{*}{ Strain } & \multirow[t]{2}{*}{ Description } & \multirow[t]{2}{*}{ Conditions } & \multicolumn{2}{|l|}{ Yields } & \multirow[t]{2}{*}{ Reference } \\
\hline & & & $\begin{array}{l}\text { Ethanol } \\
\mathrm{g} \mathrm{g}^{-1}\end{array}$ & $\begin{array}{l}\text { Xylitol } \\
\mathrm{g} \mathrm{g}^{-1}\end{array}$ & \\
\hline 1400 (pLNH32) & $X Y L 1, X Y L 2, X K S 1$ & Fermentative batch & 0.30 & 0.08 & Ho et al. (1998) \\
\hline H1691 & $X Y L 1, X Y L 2, X K S 1$ & Anaerobic batch & 0.09 & 0.41 & Toivari et al. (2001) \\
\hline H1691 & $X Y L 1, X Y L 2, X K S 1$ & Micro-aerobic batch & 0.12 & 0.42 & Toivari et al. (2001) \\
\hline H1691 & $X Y L 1, X Y L 2, X K S 1$ & Aerobic batch & 0.06 & 0.06 & Toivari et al. (2001) \\
\hline TMB 3001 & $X Y L 1, X Y L 2, X K S 1$ & Anaerobic batch & 0.31 & 0.29 & Jeppsson et al. (2002) \\
\hline TMB 3255 & $\begin{array}{l}X Y L 1, X Y L 2, X K S 1, \\
\quad \Delta z w f 1\end{array}$ & Anaerobic batch & 0.41 & 0.05 & Jeppsson et al. (2002) \\
\hline FPL-YSX3 & $X Y L 1, X Y L 2, X Y L 3$ & $\begin{array}{l}\text { Respiro fermentative } \\
\text { batch }\end{array}$ & 0.12 & 0.27 & Jin et al. (2003) \\
\hline H2674 & $X Y L 1, X Y L 2, X K S 1$ & $\begin{array}{l}\text { Anaerobic } \\
\text { batch }\end{array}$ & 0.14 & 0.53 & Verho et al. (2003) \\
\hline H2673 & $\begin{array}{l}X Y L 1, X Y L 2, X K S 1 \\
\quad G D P 1\end{array}$ & $\begin{array}{c}\text { Anaerobic } \\
\text { batch }\end{array}$ & 0.17 & 0.48 & Verho et al. (2003) \\
\hline $\mathrm{H} 2723$ & $\begin{array}{l}X Y L 1, X Y L 2, X K S 1, \\
\quad \Delta z w f 1\end{array}$ & $\begin{array}{c}\text { Anaerobic } \\
\text { batch }\end{array}$ & 0.18 & 0.28 & Verho et al. (2003) \\
\hline H2684 & $\begin{array}{l}X Y L 1, X Y L 2, X K S 1, \\
\Delta z w f 1, G D P 1\end{array}$ & $\begin{array}{c}\text { Anaerobic } \\
\text { batch }\end{array}$ & 0.34 & 0.34 & Verho et al. (2003) \\
\hline TMB3001C1 & $\begin{array}{l}\text { TMB3001 selected for } \\
\text { anaerobic growth }\end{array}$ & $\begin{array}{l}\text { Anaerobic } \\
\text { batch }\end{array}$ & 0.24 & 0.32 & $\begin{array}{l}\text { Sonderegger and } \\
\text { Sauer }(2003)\end{array}$ \\
\hline 424A(LNH-ST) & $X Y L 1, X Y L 2, X K S 1$ & Fermentative batch & 0.43 & 0.10 & Sedlak and Ho (2004) \\
\hline
\end{tabular}

Gene names used: $X Y L 1$ xylose reductase; XYL2 xylitol dehydrogenase; XKS1 and XYL3 xylulokinase; ZWF1 glucose phosphate dehydrogenase; GDP1 Glyceraldehyde 3-phophate dehydrogenase

overproduces the enzymes: xylulokinase (EC 2.7.1.17), ribulose 5-phosphate isomerase (EC 5.3.1.6), ribulose 5-phosphate epimerase (EC 5.3.1.1), transketolase (EC 2.2.1.1) and transaldolase (EC 2.2.1.2). In addition, the GRE3 gene encoding aldose reductase was deleted to further minimise xylitol production (Kuyper et al. 2005a). The resulting strain could be cultivated under anaerobic conditions without any need for selection or mutagenesis and had at that time the highest reported specific ethanol production rate
(Table 6). Again, as with RWB 202-AFX, the metabolite profiles from anaerobic batch cultivation on xylose were very similar to those of the wild type on glucose. The largest by-products were biomass and glycerol, and since the production of these products is growth-linked (Albers et al. 1996; van Dijken and Scheffers 1986) the expectation is that both can be reduced by cultivating under conditions where maintenance energy requirement and nutrient limitation prevail.

Table 6 Characteristics of xylose-fermenting strains overproducing the Piromyces xylose isomerase

\begin{tabular}{|c|c|c|c|c|c|c|}
\hline Strain & Description & $\mu_{\max } \mathrm{h}^{-1}$ & $\begin{array}{l}\text { Yield } \\
\text { ethanol } \\
\mathrm{g} \mathrm{g}^{-1}\end{array}$ & $\begin{array}{l}\text { Ethanol } \\
\text { production } \\
\mathrm{g} \mathrm{g}^{-1} \mathrm{~h}^{-1}\end{array}$ & $\begin{array}{l}\text { Xylose } \\
\text { consumption } \\
\mathrm{g} \mathrm{g}^{-1} \mathrm{~h}^{-1}\end{array}$ & $\begin{array}{l}\text { Yield xylitol } \\
\mathrm{g} \mathrm{g}^{-1}\end{array}$ \\
\hline RWB 202 & XylA & $0.005^{\mathrm{a}}$ & - & - & ND & ND \\
\hline RW 202-AFX & $\begin{array}{l}\text { Selection } \\
\text { mutant of RWB } 202\end{array}$ & 0.03 & 0.42 & 0.14 & 0.34 & 0.021 \\
\hline RWB 217 & $\begin{array}{l}\mathrm{XylA}+X K S 1 \uparrow T A L 1 \uparrow \\
\quad T K L 1 \uparrow R P E 1 \uparrow R K I 1 \uparrow \text { gre } 3 \Delta\end{array}$ & 0.09 & 0.43 & 0.46 & 1.06 & 0.003 \\
\hline RWB 218 & Selection mutant of RWB 217 & 0.12 & 0.41 & 0.49 & 1.2 & 0.001 \\
\hline
\end{tabular}

\footnotetext{
a measured under aerobic conditions

ND not determined
} 
After the initial tests in synthetic medium with xylose as the carbon source, research was focused on utilization of mixed substrates. When RWB 217 was grown in anaerobic batch culture with $20 \mathrm{~g} \mathrm{l}^{-1}$ glucose and xylose each, an exponential glucose consumption phase was observed followed by a much slower, almost linear, xylose consumption phase. Even with this suboptimal xylose consumption the metabolite profiles of RWB 217 compared very well to those on xylose alone and the wild type on glucose. To further improve the xylose consumption characteristics in mixed-substrate batch cultures, RWB 217 was subjected to evolutionary engineering (Kuyper et al. 2005b). In a first stage, xylose-uptake kinetics were improved by cultivation for 85 generations in a xylose-limited chemostat. In a second stage, the long-term chemostat culture was used to inoculate a sequencing batch reactor
(SBR) on mixtures of glucose and xylose. After 35 cycles, a single colony streaked from this SBR culture was dubbed RWB 218. When this new strain was cultivated in anaerobic batch culture with $20 \mathrm{~g} \mathrm{l}^{-1}$ glucose and xylose each, it fermented all sugars within $24 \mathrm{~h}$, an improvement of $20 \mathrm{~h}$ on RWB 217. On xylose alone RWB 218 has the highest reported specific anaerobic growth rate, xylose consumption and ethanol production rate to date (Table 6). The glucose and xylose uptake characteristics of RWB 218 had significantly changed compared to those of RWB 217. For both sugars, a doubling of the maximal uptake rate $\left(v_{\max }\right)$ was observed, and in the case of xylose a ca. $25 \%$ decrease of $K_{m}$ further contributed to improved uptake kinetics. These results lead us to conclude that the kinetics of xylose fermentation are no longer a bottleneck in the fermentation of xylose for the

Table 7 Characteristics of (recombinant) arabinose-fermenting yeasts

\begin{tabular}{|c|c|c|c|c|}
\hline Yeast strain & $\begin{array}{l}\text { Culture } \\
\text { conditions }\end{array}$ & $\begin{array}{l}\text { Final ethanol } \\
\text { concentration } \\
\left(\mathrm{g} \mathrm{l}^{-1}\right)\end{array}$ & $\begin{array}{l}\text { Ethanol } \\
\text { production } \\
\left(\mathrm{g} \mathrm{g}^{-1} \text { dry }\right. \\
\left.\text { weight } \mathrm{h}^{-1}\right)\end{array}$ & Reference \\
\hline Candida $\mathrm{sp}$ & Microaerophilic & 0.16 & & Gong et al. (1981b) \\
\hline Candida sp. XF 217 & Microaerophilic & 0.68 & & Gong et al. (1981b) \\
\hline Ambrosiozyma monospora & $\begin{array}{l}\text { Microaerophilic, } 30^{\circ} \mathrm{C} \\
\text { Moderate aeration, } 25^{\circ} \mathrm{C}\end{array}$ & $\begin{array}{l}1.8 \\
4.1\end{array}$ & & Dien et al. (1996) \\
\hline C. auringiensis & $\begin{array}{l}\text { Microaerophilic, } 30^{\circ} \mathrm{C} \\
\text { Moderate aeration, } 25^{\circ} \mathrm{C}\end{array}$ & $\begin{array}{l}1.4 \\
\text { not } \\
\quad \text { detected }\end{array}$ & & Dien et al. (1996) \\
\hline C. succiphila & $\begin{array}{l}\text { Microaerophilic, } 30^{\circ} \mathrm{C} \\
\text { Moderate aeration, } 25^{\circ} \mathrm{C}\end{array}$ & $\begin{array}{l}2.3 \\
3.9\end{array}$ & & Dien et al. (1996) \\
\hline Candida sp. (YB-2248) & $\begin{array}{l}\text { Microaerophilic, } 30^{\circ} \mathrm{C} \\
\text { Moderate aeration, } 25^{\circ} \mathrm{C}\end{array}$ & $\begin{array}{l}3.4 \\
1.7\end{array}$ & & Dien et al. (1996) \\
\hline C. arabinofermentans & Microaerophilic & $0.7-1.9$ & & $\begin{array}{l}\text { Kurtzman and Dien } \\
\text { (1998) }\end{array}$ \\
\hline $\begin{array}{l}\text { S. cerevisiae pYaraDBA } \\
\text { heterologous expression of araB, } \\
\text { ara } A \text {, and araD from E.coli }\end{array}$ & Aerobic & - & - & Sedlak et al. (2001) \\
\hline $\begin{array}{l}\text { S. cerevisiae } \mathrm{H} 2561 \\
\text { expression of fungal } \\
\text { L-arabinose pathway: lad1 } \\
\text { and lxr1 from } \\
\text { Trichoderma reesei; XYL1 } \\
\text { and XYL2 from } \\
\text { Pichia stipidis; XKS1 from } \\
\text { S. cerevisiae }\end{array}$ & Anaerobic & 0.1 & $0.35 \times 10^{-3}$ & Richard et al. (2003) \\
\hline $\begin{array}{l}\text { S. cerevisiae JBY } 25-4 \mathrm{M} \\
\text { heterologous expression of } \\
\text { B. subtilis araA, E.coli araB and araD, } \\
\text { and } S \text {. cerevisiae GAL2 }\end{array}$ & Oxygen-limited & 6 & $0.06-0.08$ & $\begin{array}{l}\text { Becker and Boles } \\
\quad(2003)\end{array}$ \\
\hline
\end{tabular}


production of bioethanol. The challenge in xylose fermentation is now to successfully transfer strains and concepts from the laboratory to industrial conditions.

\section{l-Arabinose fermentation by $S$ cerevisiae}

Although D-xylose is the most abundant pentose sugar in the hemicellulosic fraction of biomass, $\mathrm{L}$-arabinose is also present in significant amounts. Various agricultural feedstocks contain 1.5-2.75\% of L-arabinose (Table 7), thus establishing the importance of efficient conversion of L-arabinose to ethanol.

Wild-type $S$. cerevisiae strains cannot ferment or assimilate L-arabinose (Barnett et al. 1990). Although many yeasts are capable of assimilating L-arabinose aerobically, most are unable to ferment it to ethanol. In the 1980's, a few yeast species have been reported to produce small amounts of ethanol from L-arabinose (Table 7; Gong et al. 1981b). An extensive screening of 116 yeast strains resulted in the identification of four additional yeast species capable of arabinose fermentation: Ambrosiozyma monospora, Candida auringiensis, Candida succiphila, and Candida sp. NRRL YB2248 (Dien et al. 1996). Although 101 species tested could convert L-arabinose to arabinitol, only $4 \%$ of the strains screened were able to ferment L-arabinose to ethanol, with a maximum ethanol concentration of $4.1 \mathrm{~g} \mathrm{l}^{-1}$ under microaerobic conditions or moderate aeration (Table 7). Moreover, ethanol production rates observed were very low. The final ethanol concentrations (Table 7) were reached not earlier than 7-14 days after inoculation. More recently, strains of the yeast species Candida arabinofermentans were reported to produce $0.7-1.9 \mathrm{~g} \mathrm{l}^{-1}$ ethanol from L-arabinose under microaerobic conditions (Table 7; Kurtzman and Dien 1998).

The observation that, apparently, L-arabinose fermentation is rare among yeast species, may be due to a redox imbalance in the fungal arabinose pathway. In this pathway, as described for Penicillium chrysogenum (Chiang and Knight 1960) and Aspergillus niger (Witteveen et al. 1989), L-arabinose is metabolized via the reactions catalyzed by aldose (xylose) reductase, L-arabinitol 4-dehydrogenase, L-xylulose reductase, D-xylulose reductase and D-xylulokinase (Fig. 3). This pathway consists of two $\mathrm{NAD}^{+}$-linked oxidations and two NADPH-linked reductions, resulting in a redox cofactor imbalance under anaerobic conditions (Dien et al. 1996). In contrast to the strictly NADP(H)-dependent L-xylulose reductase described for the molds P. chrysogenum (Chiang and Knight 1960), A. niger (Witteveen et al. 1994), and Trichoderma reesei (Richard et al. 2002), the L-xylulose reductase of the yeast Ambrosiozyma monospora has been reported to be strictly NADH-dependent (Verho et al. 2004). It is unknown whether this is a general characteristic of this enzyme in L-arabinose-metabolizing yeasts.

Several studies have been aimed at metabolic engineering of $S$. cerevisiae for L-arabinose fermentation. Overexpression of all structural genes of the fungal L-arabinose pathway (XYL1, lad1, lxr1, XYL2, and XKS1; Table 7) resulted in the first $S$. cerevisiae strain capable of fermenting Larabinose to ethanol. However, the engineered strain produced only $0.35 \mathrm{mg}$ ethanol $\mathrm{g}^{-1} \mathrm{~h}^{-1} \mathrm{un}$ der anaerobic conditions (Richard et al. 2003). It seems probable that cofactor imbalances may have contributed to this very low ethanol production rate. Indeed, the authors suggest that the redox factor balance might be restored by a transhydrogenase activity that would interconvert $\mathrm{NADH} / \mathrm{NADP}^{+}$and $\mathrm{NAD}^{+} / \mathrm{NADPH}$. However, Nissen et al. (2000) showed that the in vivo cofactor concentrations in $S$. cerevisiae probably would not allow the reaction to proceed in the desired direction. Another way that has been proposed to ameliorate problems with cofactor imbalances is expression of the aldose reductase gene from Pi. stipitis (Rizzi et al. 1988) that also accepts NADH as cofactor, or the gene encoding NADH-dependent L-xylulose reductase $(A L X 1)$ from Ambrosiozyma monospora (Verho et al. 2004).

An alternative approach to construct an L-arabinose-fermenting $S$. cerevisiae strain is the overexpression of the bacterial L-arabinose pathway (Fig. 3). In the bacterial pathway, no redox reactions are involved in the initial steps of L-arabinose metabolism. Instead, the enzymes 
L-arabinose isomerase, L-ribulokinase, and L-ribulose-5-phosphate 4-epimerase are involved converting L-arabinose to L-ribulose, L-ribulose5-P, and D-xylulose-5-P, respectively. These enzymes are encoded by the $\operatorname{ara} A$, $\operatorname{araB}$, and $\operatorname{araD}$ genes, respectively (Lee et al. 1986). A first attempt to express the E. coli $\operatorname{ara} A$, $\operatorname{araB}$, and araD genes in $S$. cerevisiae was only partly successful. Although activities of all three enzymes were shown to be present in a yeast strain carrying the heterologous genes, the engineered strain only accumulated L-arabinitol and did not produce ethanol from L-arabinose (Sedlak and Ho 2001). Becker and Boles (2003), who followed essentially the same strategy, were more successful. In their work, the complete bacterial Larabinose pathway-consisting of E. coli araB and $a r a D$ and Bacillus subtilis araA-was introduced into $S$. cerevisiae, simultaneous with the overexpression of the yeast galactose permease gene (GAL2). Gal2p is known to transport Larabinose (Kou et al. 1970). Although overexpression of the complete arabinose pathway did not result in immediate growth on L-arabinose as the sole carbon source, the growth rate of the transformants increased progressively after 45 days of incubation (Becker and Boles 2003). Eventually, an L-arabinose-utilizing strain was selected after several sequential transfers in Larabinose medium. In addition to being able to grow aerobically on L-arabinose, the evolved $S$. cerevisiae strain produced ethanol from L-arabinose. The specific ethanol production rate under oxygen-limited conditions was $0.06-0.08 \mathrm{~g} \mathrm{~g}^{-1} \mathrm{~h}^{-1}$ (Table 7), and the ethanol yield was $60 \%$ of the maximum theoretical yield. Anaerobic fermentation of L-arabinose was not reported. The evolved strain appeared to have acquired a mutation in the L-ribulokinase gene $(\operatorname{araB})$, resulting in a reduced activity of this enzyme. An enhanced transaldolase $(T A L 1)$ activity was also reported to enhance L-arabinose fermentation. Overexpression of $G A L 2$ was found not to be essential for growth on L-arabinose, suggesting that other yeast sugar transporters can also transport Larabinose (Becker and Boles 2003).

In our opinion, Becker and Boles (2003) have convincingly demonstrated that the overexpression of the bacterial L-arabinose pathway is the most promising basis for constructing L-arabinose-fermenting $S$. cerevisiae strains. This approach circumvents the intrinsic redox imbalances associated with expression of the fungal pathway. However, while the concept seems entirely sound, additional research is required to achieve fast, efficient fermentation of L-arabinose under anaerobic conditions.

\section{Galacturonic acid}

Galacturonic acid is a sugar acid with the same configuration as D-galactose, but with a carboxylic acid group at the C6 position. Reduction of galacturonic acid to the level of a hexose requires the input of two electron pairs, for instance via two $\mathrm{NADH}$-dependent reduction steps. As a major constituent of pectin, D-galacturonic acid occurs in all plant biomass hydrolysates. Pectin-rich residues from citrus fruit, apples, sugar cane and sugar beets contain especially large amounts of Dgalacturonic acid. If D-galacturonic acid can be converted to ethanol, this would increase the relevance of these abundantly available feedstocks for the production of fuels and chemicals (Doran et al. 2000; Doran and Foster 2000; Grohmann et al. 1998; Grohmann and Bothast 1994).

Although, interestingly, some $S$. cerevisiae strains contain an endogalacturonase activity (Blanco et al. 1994; Gainvors and Belarbi 1995; Radoi et al. 2005), they cannot assimilate galacturonic acid (Barnett et al. 1990). However, this is contradicted by Gainvors and Belarbi (1995). We have not found reports on plasma membrane transport of galacturonic acid by $S$. cerevisiae, nor could we identify $S$. cerevisiae genes with a clear homology to genes encoding key enzymes in galacturonic acid metabolism (data not shown). Metabolic engineering of $S$. cerevisiae for the production of ethanol from galacturonic acid will therefore probably have to address the functional expression of a plasma membrane galacturonic acid transporter as well as a heterologous pathway for galacturonic acid catabolism. The high degree of oxidation of galacturonic acid represents a special challenge in metabolic engineering of $S$. cerevisiae for ethanol production from this substrate. 
Since the complete genome sequence is known for several yeasts and fungi that can grow on galacturonic acid, e.g. Candida and Pichia (Fellows and Worgan 1986; Fredlund et al. 2002; Kastner et al. 1999; Visser et al. 1990), it could be relatively straightforward to identify structural genes for galacturonic acid transporters by a transcriptome comparison of glucose- and galacturonic acid-grown cultures, provided such transporters are induced on galacturonic acid. Transport should preferentially be addressed before attempts are made to express a heterologous catabolic pathway, as this sequence of events allows direct screening for growth of transformants in later stages of the research.

The ability to utilize galacturonic acid is widespread among bacteria, which all seem to use essentially the same metabolic pathway (Doran et al. 2000; Fellows and Worgan 1986; Freeman and San Francisco 1994; Grohmann et al. 1998; Kilgore and Starr 1959; Serrat et al. 2004; Sirotek et al. 2004). In this bacterial pathway, D-galacturonic acid is converted to pyruvate and glyceraldehyde-3-phosphate via a five-step pathway
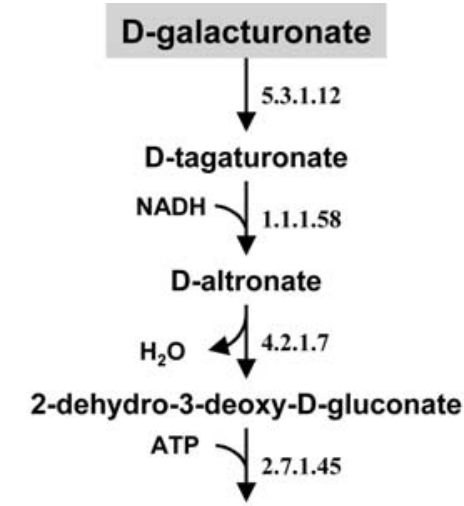

2-keto-3-deoxy-6-phosphogluconate

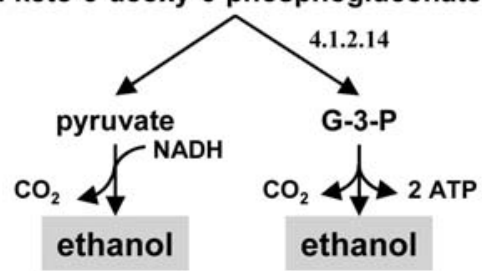

Fig. 5 Bacterial D-galacturonate catabolism. 5.3.1.12, Dgalacturonate isomerase; 1.1.1.58, altronate oxidoreductase; 4.2.1.7, altronate dehydratase; 2.7.1.45, 2-dehydro-3-deoxygluconokinase; 4.1.2.14, 2-keto-3-deoxy-6-phosphogluconate aldolase; G-3-P, glyceraldehyde-3-phosphate
(Fig. 5). Overall this results in the conversion of galacturonic acid, NADH and ATP into pyruvate, glyceraldehyde-3-phosphate and water.

Glyceraldehyde-3-phosphate can be converted to equimolar amounts of ethanol and $\mathrm{CO}_{2}$ via standard glycolytic reactions, yielding 2 ATP. However, conversion of pyruvate to ethanol requires the oxidation of a second NADH. Some galacturonic acid-metabolizing bacteria produce ethanol, but the ethanol yields are generally low (Doran et al. 2000; Grohmann et al. 1998). Reported yields are $0.19 \mathrm{~g}$ ethanol g galacturonic acid $^{-1}$ for $E$. coli and $0.12 \mathrm{~g}$ ethanol g galacturonic acid $^{-1}$ for Erwinia chrysanthemi and Klebsiella oxytoca (Doran et al. 2000). All three bacteria produced large amounts of acetate ( $0.23-$ $0.38 \mathrm{~g}$ acetate $\mathrm{g}$ galacturonic $\mathrm{acid}^{-1}$ ) (Doran et al. 2000). Clearly, a large fraction of the carbon in galacturonic acid was excreted in the form of compounds that are more oxidized than ethanol. The same problem is likely to occur upon introduction of the prokaryotic pathway into S. cerevisiae, at least when galacturonic acid is used as the sole carbon source. However, a considerably more positive scenario can be envisaged for ethanol formation from hydrolysates.

During anaerobic growth and anaerobic fermentation of sugars (hexoses, but also xylose by engineered xylose-fermenting strains) by $S$. cerevisiae, a significant fraction of the carbon is channelled into glycerol to compensate for oxidative, NADH-generating reactions in biosynthesis (Bakker et al. 2001; van Dijken and Scheffers 1986). In theory, introduction of the prokaryotic galacturonic acid fermentation route can create an alternative redox sink for the 'excess' NADH formed in biosynthesis. This would have two advantages. Firstly, the NADH derived from biosynthetic processes can be used to increase the ethanol yield on galacturonic acid to $2 \mathrm{~mol}$ ethanol per mol galacturonic acid, as the pyruvate formed from galacturonic acid can now be completely converted to ethanol. Secondly, since the sugar requirement for glycerol production is reduced, the ethanol yield on sugars will increase. The practical feasibility of this mixedsubstrate scenario will depend on the actual galacturonic acid content of the feedstock. During anaerobic growth of $S$. cerevisiae on glucose, the 
glycerol yield on glucose is ca. $0.2 \mathrm{~mol}$ glycerol mol glucose $\mathrm{e}^{-1}$, corresponding to an equimolar production of NADH from biosynthetic reductions (Verduyn et al. 1990a, b). As 2 mol $\mathrm{NADH}$ can be reoxidized during the complete alcoholic fermentation of galacturonic acid via the prokaryotic pathway for galacturonic acid metabolism, the formation of $0.2 \mathrm{~mol}$ glycerol from glucose should be redox-equivalent to the conversion of $0.1 \mathrm{~mol}$ galacturonic acid. This indicates that an engineered $S$. cerevisiae strain that expresses a functional prokaryotic pathway for galacturonic acid metabolism should be able to efficiently convert galacturonic acid when this compound is present at a molar fraction of $10 \%$ or less relative to hexose sugars. It should be mentioned that growth in large-scale ethanol production processes often results in lower biomass yields and, consequently, less generation of 'biosynthetic' NADH.

Although a large number of yeasts and molds can use galacturonic acid as a carbon and energy source for growth, knowledge of the metabolic route for $\mathrm{D}$-galacturonic acid catabolism in eukaryotes is surprisingly limited (Kuorelahti et al. 2005; Visser et al. 1988). It has been concluded that D-galacturonic acid is metabolized through glyceraldehyde and pyruvate (Visser et al. 1988). Kuorelahti et al. (2005) have recently identified a D-galacturonic acid reductase in the mold Hypocrea jecorina. This enzyme converts D-galacturonic acid and NADPH to L-galactonic acid and $\mathrm{NADP}^{+}$. It has been proposed that this enzyme may be involved in a pathway for galacturonic acid metabolism that is distinctly different from the bacterial route, and which would involve L-galactonic acid, 3-dehydroL-gulonate, L-xylulose, xylitol, D-xylulose, and xylulose 5-phosphate as intermediates (Kuorelahti et al. 2005). The NADPH-dependence of the reductase may represent a complication in yeast metabolic-engineering strategies based on this pathway as it implies a need for balancing of the two different cofactor balances $\mathrm{NADH} / \mathrm{NAD}^{+}$and NADPH/NADP ${ }^{+}$. This problem, which is reminiscent of the redox problems arising from the xylose reductase/xylitol dehydrogenase strategy for engineering xylose fermentation (see above) leads us to conclude that the prokaryotic pathway offers the most promising approach for engineering $S$. cerevisiae for galacturonic acid metabolism.

While, as described above, there appears to be a good perspective for high-yield production of ethanol from galacturonic acid in feedstocks that contain low fractions of this compound, this strategy does not offer a promising metabolic engineering approach for fermenting pectin-rich feedstocks-unless the process infrastructure allows for blending with feedstocks that have a low galacturonic acid content.

\section{Rhamnose}

The deoxyhexose L-rhamnose (6-deoxy-L-mannose, L-mannomethylose) is named after the plant it was first isolated from: the buckthorn (Rham$n u s)$. In contrast to the situation for most sugars, L-rhamnose is much more common in nature than D-rhamnose. Although rhamnose is not frequently included in the analysis of plant biomass hydrolysates, it occurs in hydrolysates as a constituent of the rhamnogalacturonan part of pectin and of hemicellulose. Being a 6-deoxy sugar, L-rhamnose is more reduced than the rapidly fermentable sugars glucose and fructose.

$S$. cerevisiae cannot grow on L-rhamnose as the sole carbon source (Barnett et al. 1990). Moreover, Yoon et al. (2003) showed the inability of immobilized $S$. cerevisiae to remove rhamnose from a carbohydrate stream under anaerobic conditions. Indeed, the $S$. cerevisiae genome does not reveal genes with a clear homology to genes encoding rhamnose-metabolizing enzymes (data not shown). Sugar-uptake studies with protoplasts and cells of glucose-pregrown $S$. cerevisiae have shown that L-rhamnose crosses the plasma membrane at an extremely low rate (ca. $2 \mu \mathrm{mol}$ $\mathrm{g}_{\text {biomass }}{ }^{-1} \mathrm{~h}^{-1}$ ) (Heredia et al. 1968). Even though rhamnose is transported about 10,000-fold slower than glucose (Bakker et al. 2000; Heredia et al. 1968), its transport is almost exclusively facilitated via hexose transporters and free diffusion hardly occurs (Heredia et al. 1968). Clearly, metabolic engineering of $S$. cerevisiae for the production of ethanol from rhamnose will have to address two key aspects: the enhancement of 
rhamnose transport across the plasma membrane and the introduction of a rhamnose-metabolizing pathway.

Two different strategies may be envisaged to achieve efficient uptake of L-rhamnose by S. cerevisiae. Firstly, after the introduction of an ATP-yielding pathway for L-rhamnose catabolism (see below), selection for growth on L-rhamnose can be used to investigate whether mutations in one or more of the hexose transporter genes in $S$. cerevisiae affect regulation and/or kinetic properties in such a way that it enables efficient Lrhamnose uptake. Alternatively, introduction of a heterologous rhamnose transporter can be considered. Although the rhamnose transporter of for instance E. coli is well characterized (Baldomá et al. 1990), functional expression of bacterial transporters in the yeast plasma membrane may be too difficult a proposition. A more promising strategy would involve the identification and expression in $S$. cerevisiae of an L-rhamnose transporter from a yeast known to utilise rhamnose (e.g. Pi. stipitis, currently being sequenced (http://www.jgi.doe.gov/sequencing/DOEmicrobes. html)). As proposed for galacturonic acid (see above) transcriptome analysis might be used to identify a rhamnose-transporter gene if such a gene is induced on rhamnose.
After its uptake, the next requirement for successful rhamnose fermentation is its conversion into intermediates of central metabolism. In 1937, Albert-Jan Kluyver (an illustrious predecessor of Gijs Kuenen), was the first to quantitatively study the metabolic fate of rhamnose (Kluyver and Schnellen 1937). By now, two pathways for Lrhamnose catabolism have been reported in microorganisms (Fig. 6). These pathways provide interesting starting points for engineering a rhamnose-utilizing route into $S$. cerevisiae.

The first catabolic pathway involves phosphorylated intermediates (Fig. 6) and is for instance used by E. coli (Wilson and Ajl 1955). In this pathway, L-rhamnose is first converted to Lrhamnulose by L-rhamnose isomerase (EC 5.3.1.14) (Takagi and Sawada 1964a; Wilson and Ajl 1957a). After subsequent phosphorylation by rhamnulokinase (EC 2.7.1.5), L-rhamnulose-1phosphate is split into dihydroxy-acetone-phosphate (DHAP) and L-lactaldehyde by rhamnulose-1-phosphate aldolase (EC 4.1.2.19) (Sawada and Takagi 1964; Takagi and Sawada 1964b; Wilson and Aj1 1957b). DHAP can be normally processed by glycolysis, yielding $1 \mathrm{~mol}$ ethanol mol L-rhamnose ${ }^{-1}$. In E. coli, further metabolism of L-lactaldehyde depends on the redox state of the cells. L-Lactaldehyde can either be oxidized to

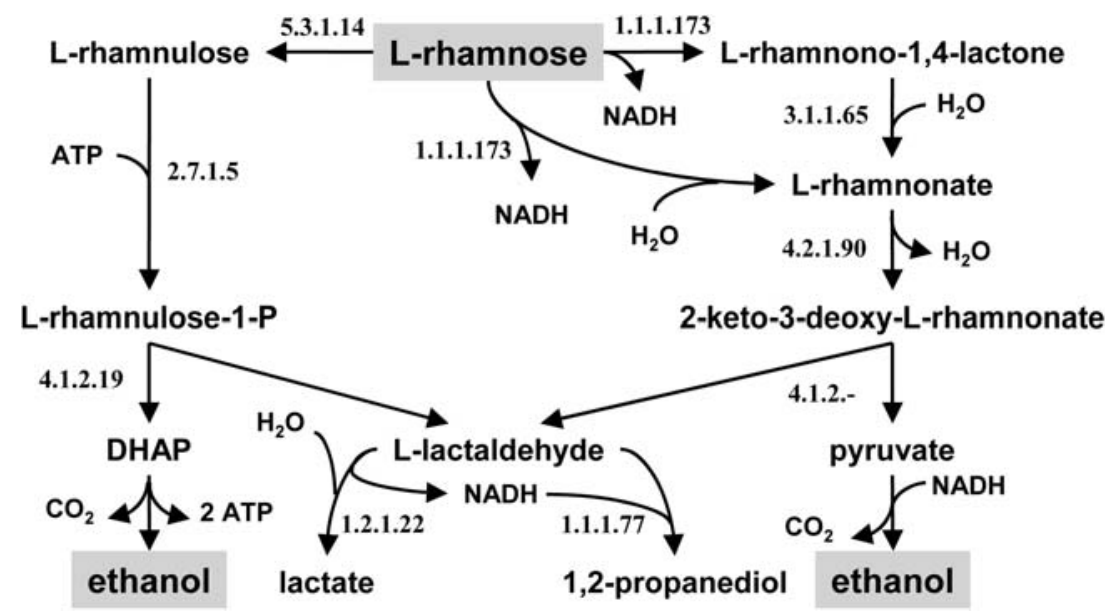

Fig. 6 Bacterial (left) and fungal (right) L-rhamnose catabolism. 5.3.1.14, L-rhamnose isomerase; 2.7.1.5, rhamnulokinase; 4.1.2.19, rhamnulose-1-phosphate isomerase; 1.1.1.173, L-rhamnose dehydrogenase; 3.1.1.65, L-rham- nono-1,4-lactonase; 4.2.1.90, L-rhamnonate dehydratase; 4.1.2.-, aldolase; 1.2.1.22, lactaldehyde dehydrogenase; 1.1.1.77, lactaldehyde reductase; DHAP, dihydroxy-acetone-phosphate 
lactate by lactaldehyde dehydrogenase (EC 1.2.1.22), reduced to 1,2-propanediol by lactaldehyde reductase (EC 1.1.1.77), or processed via a redox-neutral mix of these two reactions (Baldoma and Aguilar 1988). After introduction of this pathway into $S$. cerevisiae, conversion of L-rhamnose to equimolar amounts of ethanol, lactaldehyde and $\mathrm{CO}_{2}$ leads to the net generation of 1 ATP. This strategy would require the introduction of a transporter and three heterologous enzymes into $S$. cerevisiae (Fig. 6).

A second route for rhamnose degradation, which does not involve phosphorylated intermediates, was first described in the fungus Aureobasidium pullulans and is referred to as direct oxidative catabolism of rhamnose (Rigo et al. 1985). A similar pathway occurs in the yeasts Pichia stipitis and Debaryomyces polymorphus (Twerdochlib et al. 1994) and is initiated by the oxidation of L-rhamnose by $\mathrm{NAD}^{+}$-dependent Lrhamnose dehydrogenase (EC 1.1.1.173), yielding either L-rhamnono-1,4-lactone or the unstable rhamnono-1,5-lactone (Rigo et al. 1985; Twerdochlib et al. 1994). The 1,4 lactone is hydrolyzed to L-rhamnonate by L-rhamnono-1,4-lactonase (EC 3.1.1.65) (Rigo et al. 1985). The unstable 1,5lactone has been reported to spontaneously hydrolyse to L-rhamnonate (Twerdochlib et al. 1994). L-Rhamnonate is subsequently dehydrated to 2-keto-3-deoxy-L-rhamnonate by L-rhamnonate dehydratase (EC 4.2.1.90) (Rigo et al. 1985; Twerdochlib et al. 1994). The product of this reaction is then cleaved into pyruvate and L-lactaldehyde by an aldolase (Rigo et al. 1985; Twerdochlib et al. 1994). In Pi. stipitis the thus formed L-lactaldehyde is converted to lactate and NADH by L-lactaldehyde dehydrogenase (1.2.1.22). Introduction of this 'fungal' pathway into $S$. cerevisiae should enable the conversion of L-rhamnose to equimolar amounts of ethanol, lactaldehyde and $\mathrm{CO}_{2}$ without a net generation of ATP. This conversion would require the introduction of a transporter and four heterologous enzymes (including the 1,4-lactonase) into S. cerevisiae (Fig. 6).

At first sight, the absence of ATP formation in the direct oxidative pathway may appear beneficial, since ATP formation would enable growth of engineered $S$. cerevisiae on L-rhamnose. The resulting biomass formation would go at the expense of the ethanol yield. However, the option to select for growth on L-rhamnose during strain construction and, potentially, during long-term industrial cultivation, provides a strong incentive for using the 'bacterial' pathway instead.

Both pathways described above result in the formation of L-lactaldehyde. In anaerobic, fermenting $S$. cerevisiae cultures, the most attractive means of converting lactaldehyde is its NADHdependent reduction to 1,2-propanediol. Besides the presence, in $S$. cerevisiae, of a functional Llactaldehyde reductase, this requires one extra NADH per lactaldehyde. During anaerobic growth on sugars, S. cerevisiae normally uses glycerol formation, at a cost of 1 ATP and a lower ethanol yield, as a sink for excess reduction equivalents (Bakker et al. 2001; van Dijken and Scheffers 1986). In mixed-substrate cultures, production of 1,2-propanediol from rhamnose might function as an alternative redox sink, thereby reducing the need for glycerol production from conventional sugars and, hence, further increasing the ethanol yield.

In our opinion, it should be possible to engineer $S$. cerevisiae such that it converts half of the carbon in L-rhamnose to ethanol and $\mathrm{CO}_{2}$, with the concomitant production of equimolar amounts of 1,2-propanediol. We anticipate that the glycerol-sparing effect described above may increase the net ethanol yield from L-rhamnose in hydrolysate fermentations to $2 \mathrm{~mol} \mathrm{~mol}^{-1}$. Our recommended approach is to introduce a fungal transporter for L-rhamnose, together with the three key enzymes of the 'bacterial' pathway for L-rhamnose catabolism and an L-lactaldehyde reductase.

\section{Inhibitor tolerance}

Inhibitors in plant hydrolysates

The harsh conditions that prevail during the chemical and physical pretreatment of lignocellulose result in the release of many substances that inhibit growth and ethanol production by $S$. cerevisiae. The number and identity of these toxic compounds varies with the nature of the raw 
material and pretreatment conditions (see Klinke et al. 2004 for a recent review). There are two approaches to limit the impact of inhibitors on the fermentation process: (i) introduction of additional chemical, physical or biological process steps for removal or inactivation of inhibitors (López et al. 2004; Mussatto and Roberto 2004; Nichols et al. 2005; Palmqvist et al. 1997; Palmqvist and Hahn-Hägerdal 2000) and (ii) improvement of the tolerance of $S$. cerevisiae to the inhibitors. Physical and chemical methods of detoxification quickly become cost-prohibitive for an industry that operates with narrow profit margins. In contrast, biological methods focused on either in situ inactivation/metabolism of inhibitors or the development of more stressresistant yeast, are relatively inexpensive. In this review, we will focus on options to improve tolerance of $S$. cerevisiae to the main inhibitors in plant biomass hydrolysates.

Three major categories of inhibitory compounds derived from physico-chemical pretreatment of lignocellulosic material can be identified: weak acids, furan derivatives, and phenols (Palmqvist et al. 1999). For example, poor fermentability of dilute acid-wood hydrolysates was primarily correlated to high levels of furfural, 5hydroxymethylfurfural (5-HMF) and acetic acid (Taherzadeh et al. 1997). Therefore, these categories will be the major focus of review.

Common inhibitors in hydrolysates, effects and mechanisms

Of the many weak organic acids that occur in lignocellulose hydrolysates, acetic acid is most common to hemicellulose hydrolysates (Ingram et al. 1999), while hydroxycarboxylic acids like glycolic acid and lactic acid are also present when alkaline hydrolysis is performed (Sjöström 1991). Furthermore, formic acid is generated by degradation of sugars or lignin (Klinke et al. 2002) with levulinic acid commonly arising from 5-HMF degradation (Palmqvist et al. 1999).

As undissociated weak organic acids readily diffuse across biological membranes and the $\mathrm{pH}$ of the yeast cytosol is generally higher than that of the surrounding medium, internal hydrolysis of weak acids causes cytosolic acidification
(Pampulha and Loureiro-Dias 1989), which has to be compensated for by ATP-dependent proton pumping (Holyoak et al. 1996; Imai and Ohno 1995; Verduyn et al. 1992). In addition, intracellular accumulation of the anion, either by itself or in combination with intracellular acidification, can lead to toxic effects (Casal et al. 1996; Eklund 1983; Pampulha and Loureiro-Dias 1990; Russell 1992). Benzoate, for instance, has been implicated in inhibition of autophagy (Hazan et al. 2004) and acetate has been demonstrated to induce apoptosis (Ludovico et al. 2001). Moreover, hydrolysates contain many compounds that act synergistically with organic acids. Such synergistic effects have been demonstrated for various combinations of acids, phenols and furans (Nigam 2001; Palmqvist et al. 1999). Ethanol has also been reported to augment the toxicity of weak acids (Leão and Van Uden 1984; Pampulha and Loureiro-Dias 1989).

The predominant furan derivatives, furfural and 5-HMF, which are mainly derived from dehydration of pentose and hexose sugars during hydrolysis, are among the strongest inhibitors in lignocellulosic hydrolysates (Taherzadeh et al. 1997). Although furfural is more toxic than 5-HMF, both compounds act synergistically to suppress yeast growth (Liu et al. 2004). In general, furans have been implicated in a broad range of effects, including inhibition of cell growth and glucose utilization, reduction of enzymic activity and ethanol productivity, DNA damage and inhibition of protein and RNA synthesis (as cited in Liu et al. 2004). However, S. cerevisiae is capable of reducing furfural and 5-HMF to the less toxic furfuryl (Taherzadeh et al. 1999) and 5hydroxymethyl furfuryl alcohols (Taherzadeh et al. 2000), respectively. When present alone, furfural is converted so efficiently that inhibitory effects decrease with increasing cell mass due to its rapid bioconversion (Navarro 1994). Increasing the biomass concentration via biomass recycling similarly reduced the impact of furans on ethanol productivity (Brandberg et al. 2005). Conversely, conversion rates of both compounds are decreased when they are present in combination (Taherzadeh et al. 2000) with furfural being converted at higher rates (Larsson et al. 1999) and HMF metabolism only proceeding 
after the complete degradation of furfural (Taherzadeh et al. 2000).

Finally, various phenolic compounds that are derived from lignin degradation have a significant impact on fermentation of hydrolysates. Due to its abundance in hardwood hydrolysates (Jönsson et al. 1998), 4-hydroxybenzoic acid is often used as a model compound to study the effects of phenolics. Other phenols, including vanillin, vanillic acid, hydroxybenzaldehyde, syringaldehyde, catechol, resorcinol, and salicylic acid have also been studied (as cited in Palmqvist and Hahn-Hägerdal 2000). These compounds are toxic (Buchert et al. 1989) because they compromise the integrity of biological membranes (Heipieper et al. 1994).

Improving inhibitor tolerance of $S$. cerevisiae

The tolerance towards inhibitors in plant biomass hydrolysates differs considerably among $S$. cerevisiae strains (Sonderegger et al. 2004). Therefore, depending on the composition of the biomass hydrolysates and the complexity of the intended metabolic engineering strategy, it may be useful to select a host strain with an appropriate inhibitor tolerance. Where increased tolerance is required for successful industrial application, this can be approached via metabolic engineering, evolutionary engineering (Sauer 2001), or a combination thereof.

Increased furan resistance of $S$. cerevisiae has been realized by accumulation of furan-selective mutants via serial transfer in the presence of increasing furan concentrations (Liu et al. 2005). The resulting strains were capable of complete reduction of $60 \mathrm{mM} \mathrm{HMF}$ and $30 \mathrm{mM}$ furfural to the corresponding alcohols. Furthermore, genetic engineering strategies to increase furan tolerance are likely to be proposed in the near future as Gorsich et al. (2005) have demonstrated that deletion of the pentose-phosphate-pathway genes, ZWF1, GND1, RPE1 and TLK1, negatively affects furfural tolerance. Although NADPH, which is primarily generated via the pentose-phosphate pathway, is required for $\mathrm{HMF}$ reduction (Flores et al. 2000; Wahlbom and Hahn-Hägerdal 2002), furfural reduction has been linked to NADH (Wahlbom and
Hahn-Hägerdal 2002). However, it has been suggested that decreased NADPH generation reduces the overall reduction potential of the cell, thus leaving less NADH for furfural reduction (Gorsich et al. 2005). Similarly, Nilsson et al. (2005) have reported that the furan reduction capacity is key to performance of a yeast strain in lignocellulosic hydrolysates. This identifies both cofactor recycling and the capacity of the alcohol dehydrogenase(s) involved in furan reduction as key targets for metabolic engineering.

The toxicity of phenols has been successfully reduced by the addition of laccase (EC 1.10.3.2) to hydrolysates (Jönsson et al. 1998). Expression of the Trametes versicolor laccase gene into S. cerevisiae (Larsson et al. 2001a) resulted in decreased fermentation times on hydrolysates, while overexpression of a phenylacrylic-acid decarboxylase resulted in improved growth rate and ethanol productivity in dilute-acid hydrolysates (Larsson et al. 2001b). Contrarily, metabolic or evolutionary engineering studies to improve the tolerance of $S$. cerevisiae to the weak organic acids that are present in the hydrolysates are rare. However, successes in different backgrounds, such as for instance an acetate-tolerant (6-8 $\left.\mathrm{g} \mathrm{l}^{-1}\right)$ $S$. cerevisiae strain selected for use in sour dough (Aarnio et al. 1991), could be extrapolated to hydrolysate fermentation.

Evidently, the vast array of inhibitors present in lignocellulose hydrolysates presents a formidable challenge for biologists and engineers alike. Although numerous detoxification strategies and yeast strains have been investigated, an ideal and generic solution has not yet been identified. Most likely, hydrolysate-specific combinations of detoxification methods with tailor-made yeast strains will play a major role in industrial research. Additionally, advances in pretreatment and separation technology may have a major impact by minimizing the formation of inhibitors.

\section{Outlook}

Given the economic and environmental importance of a closed carbon cycle in transport fuel production, construction of strains that efficiently convert all fermentable substrates in plant biomass 
into ethanol is, perhaps, the single most important challenge in yeast metabolic engineering.

In terms of volume, xylose is the most abundant sugar in plant biomass hydrolysates that cannot be fermented by wild-type $S$. cerevisiae strains. The recent breakthroughs with xylose-isomeraseexpressing strains (Kuyper et al. 2005b) illustrate a number of issues that, in our opinion, are of paramount importance for achieving fast and efficient alcoholic fermentation of additional compounds in a time-efficient manner. These include:

1. The metabolic-engineering strategy should enable a closed balance of relevant redox cofactors $\left(\mathrm{NAD}^{+} / \mathrm{NADH}\right.$ and $\mathrm{NADP}^{+} /$ NADPH).

2. Catalytic activity of heterologous enzymes and transporters in $S$. cerevisiae may require extensive screening. Whereas the discovery of the Piromyces xylose isomerase (Harhangi et al. 2003) was, to some extent, serendipitous, it underscores that screening of culture collections and/or metagenomics (Schloss and Handelsman 2003) approaches may be required for identification of enzymes with optimal properties.

3. Directed evolution of wild-type or metabolically-engineered microbial cultures (evolutionary engineering, Sauer 2001) is a powerful approach in scenarios where performance of microbial strains is directly linked to specific growth rate. As long as an engineered pathway for ethanol production results in a net ATP gain, this approach should be applicable to all substrates discussed above.

As demonstrated above, promising strategies are available for a further expansion of the substrate range of ethanol-producing $S$. cerevisiae strains, probably starting with the full optimization of the bacterial L-arabinose pathway (Becker and Boles 2003; Sedlak and Ho 2001). We are confident that a concerted, multidisciplinary effort in yeast metabolic engineering will result in rapid progress in the areas discussed in this review.

However important, proof-of-principle experiments under 'academic' conditions (synthetic media, single substrates or simple substrate mixtures, absence of toxic inhibitors) merely represent the first step towards industrially applicable strains. Efficient conversion of complex substrate mixtures in the presence of synergistically acting inhibitors needs to be addressed before industrial implementation can be contemplated. Given the diversity of feedstocks as well as of methods for producing plant biomass hydrolysates, it appears prudent to integrate studies on hydrolysate preparation and strain optimization from an early stage onwards.

Once the crucial issues related to substrate range and inhibitor tolerance have been successfully addressed, a next key target for yeast-based ethanol research is likely to be the 'consolidated bioprocessing' approach (Lynd et al. 2005), i.e. the functional expression of cellulolytic enzymes and other hydrolases in ethanol-producing microbial strains. Despite the recent dramatic reductions of the costs of hydrolytic enzymes, by amongst others Genencor, Novozymes and NREL, it seems probable that the ultimate 'cell factory' for ethanol production will integrate fermentation with at least some of the major catalytic activities required for polymer degradation.

Its role in current large-scale ethanol production, genetic accessibility and robustness under process conditions make $S$. cerevisiae the most promising platform for process development and optimization in the coming decade. This statement should not be interpreted as overly conservative or, indeed, protective. We strongly advocate that, in addition to major public and private investments in $S$. cerevisiae-oriented bioethanol research, substantial support be given to alternative platforms such as cellulolytic thermophilic microorganisms.

Acknowledgements The research group of JTP is part of the Kluyver Centre for Genomics of Industrial Fermentation, which is supported by the Netherlands Genomics Initiative. HWW is supported by the B-Basic Programme, JvdB by the IOP Genomics Programme and DAA by Tate \& Lyle Ingredients Americas.

\section{References}

Aarnio TH, Suihko ML, Kauppinen VS (1991) Isolation of acetic acid-tolerant bakers-yeast variants in a turbidostat. Appl Biochem Biotechnol 27:55-63 
Albers E, Larsson C, Lidén G, Niklasson C, Gustafsson L (1996) Influence of the nitrogen source on Saccharomyces cerevisiae anaerobic growth and product formation. Appl Environ Microbiol 62:3187-3195

Andreasen AA, Stier TJ (1953) Anaerobic nutrition of Saccharomyces cerevisiae. I. Ergosterol requirement for growth in a defined medium. J Cell Physiol 41:23-36

Andreasen AA, Stier TJ (1954) Anaerobic nutrition of Saccharomyces cerevisiae. II. Unsaturated fatty acid requirement for growth in a defined medium. J Cell Physiol 43:271-281

Aristidou A, Penttilä M (2000) Metabolic engineering applications to renewable resource utilization. Curr Opin Biotechnol 11:187-198

Baciu IE, Jördening HJ (2004) Kinetics of galacturonic acid release from sugar-beet pulp. Enzyme Microb Technol 34:505-512

Bakker BM, Bro C, Kötter P, Luttik MAH, van Dijken JP, Pronk JT (2000) The mitochondrial alcohol dehydrogenase Adh3p is involved in a redox shuttle in Saccharomyces cerevisiae. J Bacteriol 182:4730-4737

Bakker BM, Overkamp KM, van Maris AJ, Kötter P, Luttik MA, van Dijken JP, Pronk JT (2001) Stoichiometry and compartmentation of NADH metabolism in Saccharomyces cerevisiae. FEMS Microbiol Rev 25:15-37

Baldoma L, Aguilar J (1988) Metabolism of L-fucose and L-rhamnose in Escherichia coli: aerobic-anaerobic regulation of L-lactaldehyde dissimilation. J Bacteriol 170:416-421

Baldomá L, Badia J, Sweet G, Aguilar J (1990). Cloning, mapping and gene-product identification of rha $\mathrm{T}$ from Escherichia coli K12. FEMS Microbiol Lett 72:103-108

Barnett JA, Payne RW, Yarrow D (1990) Yeasts; Characteristics and identification. Cambridge University Press, Cambridge, UK. ISBN 0-521-35056-5

Becker J, Boles E (2003) A modified Saccharomyces cerevisiae strain that consumes L-arabinose and produces ethanol. Appl Environ Microbiol 69:41444150

Bigg GR, Jickells TD, Liss PS, Osborn TJ (2003) The role of the oceans in climate. Int J Climatol 23:1127-1159

Blanco P, Sieiro C, Díaz A, Villa TG (1994) Production and partial characterization of an endopolygalacturonase from Saccharomyces cerevisiae. Can J Microbiol 40:974-977

Blank LM, Lehmbeck F, Sauer U (2005) Metabolic-flux and network analysis in fourteen hemiascomycetous yeasts. FEMS Yeast Res 5:545-558

Blow DM, Hartley BS, Henrick K (1990) Xylose isomerase mutants. Pat. no. WO 9000196. Appl. no. 89GB748

Boles E, Hollenberg CP (1997) The molecular genetics of hexose transport in yeasts. FEMS Microbiol Rev 21:85-111

Brandberg T, Sanandaji N, Gustafsson L, Franzén CJ (2005) Continuous fermentation of undetoxified dilute acid lignocellulose hydrolysate by Saccharomyces cerevisiae ATCC 96581 using cell recirculation. Biotechnol Prog 21:1093-1101
Bro C, Knudsen S, Regenberg B, Olsson L, Nielsen J (2005) Improvement of galactose uptake in Saccharomyces cerevisiae through overexpression of phosphoglucomutase: example of transcript analysis as a tool in inverse metabolic engineering. Appl Environ Microbiol 71:6465-6472

Bruinenberg PM, de Bot PHM, van Dijken JP, Scheffers WA (1983a) The role of the redox balance in the anaerobic fermentation of xylose by yeasts. Eur J Appl Microbiol Biotechnol 18:287-292

Bruinenberg PM, de Bot PHM, van Dijken JP, Scheffers WA (1984) NADH-linked aldose reductase: the key to ethanolic fermentation of xylose by yeasts. Appl Microbiol Biotechnol 19:256-260

Bruinenberg PM, van Dijken JP, Scheffers WA (1983b) An enzymic analysis of NADPH production and consumption in Candida utilis. J Gen Microbiol 129:965-971

Buchert J, Puls J, Poutanen K (1989) The use of steamed hemicellulose as substrate in microbial conversions. Appl Biochem Biotechnol 20-1:309-318

Casal M, Cardoso H, Leão C (1996) Mechanisms regulating the transport of acetic acid in Saccharomyces cerevisiae. Microbiology 142:1385-1390

Chen Z, Ho NWY (1993) Cloning and improving the expression of Pichia stipitis xylose reductase gene in Saccharomyces cerevisiae. Appl Biochem Biotechnol 39-40:135-147

Chiang GC, Knight SG (1960) A new pathway of pentose metabolism. Biochem Biophys Res Commun 3:554559

Claassen PAM, van Lier JB, Lopez-Cóntreras AM, van Niel EWJ, Sijtsma L, Stams AJM, de Vries SS, Weusthuis RA (1999) Utilisation of biomass for the supply of energy carriers. Appl Microbiol Biotechnol 52:741-755

Demain AL, Newcomb M, Wu JHD (2005) Cellulase, Clostridia, and ethanol. Microbiol Mol Biol Rev 69:124-154

Dien BS, Cotta MA, Jeffries TW (2003) Bacteria engineered for fuel ethanol production: current status. Appl Microbiol Biotechnol 63:258-266

Dien BS, Kurtzman CP, Saha BC, Bothast RJ (1996) Screening for L-arabinose fermenting yeasts. Appl Biochem Biotechnol 57-58:233-242

Domingues L, Dantas MM, Lima N, Teixeira JA (1999a) Continuous ethanol fermentation of lactose by a recombinant flocculating Saccharomyces cerevisiae strain. Biotechnol Bioeng 64:692-697

Domingues L, Teixeira JA, Lima N (1999b) Construction of a flocculent Saccharomyces cerevisiae fermenting lactose. Appl Microbiol Biotechnol 51:621-626

Doran JB, Cripe J, Sutton M, Foster B (2000) Fermentations of pectin-rich biomass with recombinant bacteria to produce fuel ethanol. Appl Biochem Biotechnol 84-86:141-152

Doran JB, Foster B (2000) Ethanol production from sugar beet pulp using engineered bacteria. Int Sugar J 102:336-340

Douglas HC, Hawthorne DC (1964) Enzymatic expression and genetic linkage of genes controlling galactose utilization in Saccharomyces. Genetics 49:837-844 
Eklund T (1983) The antimicrobial effect of dissociated and undissociated sorbic acid at different $\mathrm{pH}$ levels. J Appl Bacteriol 54:383-389

Eliasson A, Christensson C, Wahlbom CF, Hahn-Hägerdal B (2000) Anaerobic xylose fermentation by recombinant Saccharomyces cerevisiae carrying XYL1, $X Y L 2$, and $X K S 1$ in mineral medium chemostat cultures. Appl Environ Microbiol 66:3381-3386

Fellows PJ, Worgan JT (1986) Studies on the growth of Candida utilis on D-galacturonic acid and the products of pectin hydrolysis. Enzyme Microb Technol 9:537540

Flores CL, Rodriguez C, Petit T, Gancedo C (2000) Carbohydrate and energy-yielding metabolism in nonconventional yeasts. FEMS Microbiol Rev 24:507-529

Fredlund E, Blank LM, Schnürer J, Sauer U, Pasoth V (2002) Oxygen- and glucose- dependent regulation of central carbon metabolism in Pichia anomala. Appl Environ Microbiol 70:5905-5911

Freeman TL, San Francisco MJ (1994) Cloning of a galacturonic acid uptake gene from Erwinia chrysanthemi EC16. FEMS Microbiol Lett 118:101-106

Fukazawa C (1989) Cloning of a gene encoding glucose isomerase from Streptomyces and its expression. Pat. no. JP 01137979. Appl. no. 87-295739

Gainvors A, Belarbi A (1995) Detection method for polygalacturonase-producing strains of Saccharomyces cerevisiae. Yeast 11:1493-1499

Galbe M, Zacchi G (2002) A review of the production of ethanol from softwood. Appl Microbiol Biotechnol 59:618-628

Gárdonyi M, Hahn-Hägerdal B (2003) The Streptomyces rubiginosus xylose isomerase is misfolded when expressed in Saccharomyces cerevisiae. Enzyme Microb Technol 32:252-259

Gong CS, Chen LF, Flickinger MC, Chiang LC, Tsao GT (1981a). Production of ethanol from D-xylose by using D-xylose isomerase and yeasts. Appl Environ Microbiol 41:430-436

Gong CS, McCracken LD, Tsao GT (1981b). Direct fermentation of D-xylose to ethanol by a xylose-fermentating yeast mutant, Candida sp Xf217. Biotechnol Lett 3:245-250

Gorsich SW, Dien BS, Nichols NN, Slininger PJ, Liu ZL, Skory CD (2005) Tolerance to furfural-induced stress is associated with pentose phosphate pathway genes ZWF1, GND1, RPE1, and TKL1 in Saccharomyces cerevisiae. Appl Microbiol Biotechnol 1-11

Greene DL, Hopson JL, Li J (2002) Running into and out of oil: scenarios of global oil use and resource depletion to 2050. 1-65. 2002. U.S. Dept. of Energy. Tennessee, Knoxville, DE-AC05-00OR22725

Grohmann K, Bothast RJ (1994). Pectin rich residues generated by processing of citrus fruits, apples, and sugar beets. Enzymatic hydrolysis and biological conversion to value-added products. Enzymatic Conversion of Biomass for Fuels Production, Oxford University Press, Oxford, UK pp 372-390

Grohmann K, Manthey JA, Cameron RG, Buslig BS (1998) Fermentation of galacturonic acid and pectin- rich materials to ethanol by genetically modified strains of Erwinia. Biotechnol Lett 20:195-200

Gunsalus IC, Horecker BL, Wood WA (1955) Pathways of carbohydrate metabolism in microorganisms. Bacteriol Rev 19:79-128

Hahn-Hägerdal B, Linden T, Senac T, Skoog K (1991) Ethanolic fermentation of pentoses in lignocellulose hydrolyzates. Appl Biochem Biotechnol 28-29:131144

Harhangi HR, Akhmanova AS, Emmens R, van der Drift C, de Laat WT, van Dijken JP, Jetten MS, Pronk JT, Op den Camp HJ, (2003) Xylose metabolism in the anaerobic fungus Piromyces sp. E2 follows the bacterial pathway. Arch Microbiol 180:134-141

Hazan R, Levine A, Abeliovich H (2004) Benzoic acid, a weak organic acid food preservative, exerts specific effects on intracellular membrane trafficking pathways in Saccharomyces cerevisiae. Appl Environ Microbiol 70:4449-4457

Heipieper HJ, Weber F, Sikkema J, Keweloh H, de Bont JAM (1994) Mechanisms of resistance of whole cells to toxic organic solvents. Trends Biotechnol 12:409415

Heredia CF, Sols A, DelaFuente G (1968) Specificity of the constitutive hexose transport in yeast. Eur J Biochem 5:321-329

Ho NWY, Chen Z, Brainard AP (1998) Genetically engineered Saccharomyces yeast capable of effective cofermentation of glucose and xylose. Appl Environ Microbiol 64:1852-1859

Ho NWY, Stevis P, Rosenfeld S, Huang JJ, Tsao GT (1984) Expression of the E. coli xylose isomerase gene by a yeast promoter. Biotechnol Bioeng Symp 13:245250

Holden H, Cooper-Key D, Carlill P, Hinchcliff H, Heath W, Black W, Ormandy DHM (1919) Petroleum executive: report of the inter- departmental committee on various matters concerning the production and utilization of alcohol for power and traction purposes. (117-124). HMSO. Cd.218

Holyoak CD, Stratford M, McMullin Z, Cole MB, Crimmins K, Brown AJ, Coote PJ (1996) Activity of the plasma membrane $\mathrm{H}(+)$-ATPase and optimal glycolytic flux are required for rapid adaptation and growth of Saccharomyces cerevisiae in the presence of the weak-acid preservative sorbic acid. Appl Environ Microbiol 62:3158-3164

Horak J, Wolf DH (1997) Catabolite inactivation of the galactose transporter in the yeast Saccharomyces cerevisiae: ubiquitination, endocytosis, and degradation in the vacuole. J Bacteriol 179:1541-1549

Howard RL, Abotsi E, Jansen van Rensburg E, Howard S (2003) Lignocellulose biotechnology: issues of bioconversion and enzyme production. African J Biotech 2:602-619

Hsiao HY, Chiang LC, Chen LF, Tsao GT (1982) Effects of borate on isomerization and yeast fermentation of high xylulose solution and acid hydrolysate of hemicellulose. Enzyme Microb Technol 4:25-31 
Imai T, Ohno T (1995) The relationship between viability and intracellular $\mathrm{pH}$ in the yeast Saccharomyces cerevisiae. Appl Environ Microbiol 61:3604-3608

Ingram LO, Aldrich HC, Borges AC, Causey TB, Martinez A, Morales F, Saleh A, Underwood SA, Yomano LP, York SW, Zaldivar J, Zhou S (1999) Enteric bacterial catalysts for fuel ethanol production. Biotechnol Prog 15:855-866

Iogen Corporation (2005) Cellulose ethanol: clean fuel for today and tomorrow. Iogen Corporation, Ottawa, Canada

Jeffries TW, Jin YS (2004). Metabolic engineering for improved fermentation of pentoses by yeasts. Appl Microbiol Biotechnol 63:495-509

Jeppsson M, Johansson B, Hahn-Hägerdal B, GorwaGrauslund MF (2002) Reduced oxidative pentose phosphate pathway flux in recombinant xylose-utilizing Saccharomyces cerevisiae strains improves the ethanol yield from xylose. Appl Environ Microbiol 68:1604-1609

Jin YS, Ni H, Laplaza JM, Jeffries TW (2003) Optimal growth and ethanol production from xylose by recombinant Saccharomyces cerevisiae require moderate D-xylulokinase activity. Appl Environ Microbiol 69:495-503

Johnston M, Flick JS, Pexton T (1994) Multiple mechanisms provide rapid and stringent glucose repression of GAL gene expression in Saccharomyces cerevisiae. Mol Cell Biol 14:3834-3841

Johnston SA, Salmeron JM, Dincher SS (1987) Interaction of positive and negative regulatory proteins in the galactose regulon of yeast. Cell 50:143-146

Jönsson LJ, Palmqvist E, Nilvebrant NO, Hahn-Hägerdal B (1998) Detoxification of wood hydrolyzates with laccase and peroxidase from the white-rot fungus Trametes versicolor. Appl Microbiol Biotechnol 49:691-697

Kamp AF, La Rivière JWM, Verhoeven W (1959) Albert Jan Kluyver his life and his work; biographical memoranda, selected papers, bibliography and addenda. NHPC, Amsterdam

Karhumaa K, Hahn-Hägerdal B, Gorwa-Grauslund MF (2005) Investigation of limiting metabolic steps in the utilization of xylose by recombinant Saccharomyces cerevisiae using metabolic engineering. Yeast 22:359368

Kastner JR, Jones WJ, Roberts RS (1999) Oxygen starvation induces cell death in Candida shehatae fermentations of D-xylose, but not D-glucose. Appl Microbiol Biotechnol 51:780-785

Keating JD, Robinson J, Cotta MA, Saddler JN, Mansfield SD (2004) An ethanologenic yeast exhibiting unusual metabolism in the fermentation of lignocellulosic hexose sugars. J Ind Microbiol Biotechnol 31:235-244

Khandekar ML, Murty TS, Chittibabu P (2005) The global warming debate: a review of the state of science. Pure Appl Geophys 162:1557-1586

Kilgore WW, Starr MP (1959) Catabolism of galacturonic and glucuronic acids by Erwinia carotovoro. J Biol Chem 234:2227-2235
Klare MT (2001) The new geography of conflict. Foreign Aff 80:49

Klinke HB, Ahring BK, Schmidt AS, Thomsen AB (2002) Characterization of degradation products from alkaline wet oxidation of wheat straw. Bioresour Technol $82: 15-26$

Klinke HB, Thomsen AB, Ahring BK (2004) Inhibition of ethanol-producing yeast and bacteria by degradation products produced during pre-treatment of biomass. Appl Microbiol Biotechnol 66:10-26

Kluyver AJ (1914) Thesis: Biochemische suikerbepalingen. Delft University of Technology

Kluyver AJ, Schnellen Ch (1937) Über die Vergärung von Rhamnose. Enzymologia 4:7-12

Kötter P, Amore R, Hollenberg CP, Ciriacy M (1990) Isolation and characterization of the Pichia stipitis xylitol dehydrogenase gene, $X Y L 2$, and construction of a xylose-utilizing Saccharomyces cerevisiae transformant. Curr Genet 18:493-500

Kötter P, Ciriacy M (1993) Xylose fermentation by Saccharomyces cerevisiae. Appl Microbiol Biotechnol 38:776-783

Kou SC, Christensen MS, Cirillo VP (1970) Galactose transport in Saccharomyces cerevisiae. 2. Characteristics of galactose uptake and exchange in galacktokinaseless cells. J Bacteriol 103:671-678

Kressmann FW (1922) The manufacture of ethyl alcohol from wood waste. U.S. Dep. Agric. Bull. 983

Kruckeberg AL (1996) The hexose transporter family of Saccharomyces cerevisiae. Arch Microbiol 166:283292

Kuorelahti S, Kalkkinen N, Penttilä M, Londesborough J, Richard P (2005) Identification in the mold Hypocrea jecorina of the first fungal D-galacturonic acid reductase. Biochemistry 44:11234-11240

Kurtzman CP, Dien BS (1998) Candida arabinofermentans, a new L-arabinose fermenting yeast. Antonie van Leeuwenhoek 74:237-243

Kuyper M, Harhangi HR, Stave AK, Winkler AA, Jetten MS, de Laat WT, de Ridder JJ, Op den Camp HJ, van Dijken JP, Pronk JT (2003) High-level functional expression of a fungal xylose isomerase: the key to efficient ethanolic fermentation of xylose by Saccharomyces cerevisiae? FEMS Yeast Res 4:69-78

Kuyper M, Hartog MM, Toirkens MJ, Almering MJ, Winkler AA, van Dijken JP, Pronk JT (2005a) Metabolic engineering of a xylose-isomerase-expressing Saccharomyces cerevisiae strain for rapid anaerobic xylose fermentation. FEMS Yeast Res 5:399-409

Kuyper M, Toirkens MJ, Diderich JA, Winkler AA, van Dijken JP, Pronk JT (2005b) Evolutionary engineering of mixed-sugar utilization by a xylose-fermenting Saccharomyces cerevisiae strain. FEMS Yeast Res 5:925-934

Kuyper M, Winkler AA, van Dijken JP, Pronk JT (2004) Minimal metabolic engineering of Saccharomyces cerevisiae for efficient anaerobic xylose fermentation: a proof of principle. FEMS Yeast Res 4:655-664

Larsson S, Cassland P, Jönsson LJ (2001a) Development of a Saccharomyces cerevisiae strain with enhanced resistance to phenolic fermentation inhibitors in 
lignocellulose hydrolysates by heterologous expression of laccase. Appl Environ Microbiol 67:1163-1170

Larsson S, Nilvebrant NO, Jönsson LJ (2001b). Effect of overexpression of Saccharomyces cerevisiae Pad1p on the resistance to phenylacrylic acids and lignocellulose hydrolysates under aerobic and oxygenlimited conditions. Appl Microbiol Biotechnol 57:167-174

Larsson S, Palmqvist E, Hahn-Hägerdal B, Tengborg C, Stenberg K, Zacchi G, Nilvebrant NO (1999) The generation of fermentation inhibitors during dilute acid hydrolysis of softwood. Enzyme Microb Technol 24:151-159

Leão C, Van Uden N (1984) Effects of ethanol and other alkanols on passive proton influx in the yeast Saccharomyces cerevisiae. Biochim Biophys Acta 774:43-48

Lee N, Gielow W, Martin R, Hamilton E, Fowler A (1986) The organization of the araBAD operon of Escherichia coli. Gene 47:231-244

Lee RL (1997) Overview and evaluation of fuel ethanol from cellulosic biomass: technology, economics, the environment and policy. Annu Rev Energy Environ 21:403-465

Leloir LF (1951) The enzymatic transformation of uridine diphosphate glucose into a galactose derivative. Arch Biochem Biophys 33:186-190

Leuther KK, Johnston SA (1992) Nondissociation of $G A L 4$ and $G A L 80$ in vivo after galactose induction. Science 256:1333-1335

Liu ZL, Slininger PJ, Dien BS, Berhow MA, Kurtzman CP, Gorsich SW (2004) Adaptive response of yeasts to furfural and 5-hydroxymethylfurfural and new chemical evidence for HMF conversion to 2,5-bishydroxymethylfuran. J Ind Microbiol Biotechnol 31:345-352

Liu ZL, Slininger PJ, Gorsich SW (2005) Enhanced biotransformation of furfural and hydroxymethylfurfural by newly developed ethanologenic yeast strains. Appl Biochem Biotechnol 121-124:451-460

López MJ, Nichols NN, Dien BS, Moreno J, Bothast RJ (2004) Isolation of microorganisms for biological detoxification of lignocellulosic hydrolysates. Appl Microbiol Biotechnol 64:125-131

Ludovico P, Sousa MJ, Silva MT, Leão C, Côrte-Real M (2001) Saccharomyces cerevisiae commits to a programmed cell death process in response to acetic acid. Microbiology 147:2409-2415

Lugar R, Woolsey RJ (1999) The new petroleum. Foreign Aff 78:88-102

Lynd LR (1996) Overview and evaluation of fuel ethanol from cellulosic biomass: technology, economics, the environment, and policy. Annu Rev Energy Environ 21:403-465

Lynd LR, van Zyl WH, McBride JE, Laser M (2005) Consolidated bioprocessing of cellulosic biomass: an update. Curr Opin Biotechnol 16:577-583

Lynd LR, Weimer PJ, van Zyl WH, Pretorius IS (2002) Microbial cellulose utilization: fundamentals and biotechnology. Microbiol Mol Biol Rev 66:506-577

Melcher K (1997) Galactose metabolism in Saccharomyces cerevisiae: a paradigm for eukaryotic gene regulation.
Yeast sugar metabolism. Technomic Publishing Inc., Lancaster PA, pp 235-269

Micard V, Renard CMGC, Thibault JF (1996) Enzymatic saccharification of sugar-beet pulp. Enzyme Microb Technol 19:162-170

Moes CJ, Pretorius IS, van Zyl WH (1996) Cloning and expression of the Clostridium thermosulfurogenes Dxylose isomerase gene (xylA) in Saccharomyces cerevisiae. Biotechnol Lett 18:269-274

Mussatto SI, Roberto IC (2004) Alternatives for detoxification of diluted-acid lignocellulosic hydrolyzates for use in fermentative processes: a review. Bioresour Technol 93:1-10

Navarro AR (1994) Effects of furfural on ethanol fermentation by Saccharomyces cerevisiae: mathematical models. Curr Microbiol 29:87-90

Nehlin JO, Carlberg M, Ronne H (1991) Control of yeast GAL genes by MIG1 repressor: a transcriptional cascade in the glucose response. EMBO J 10:3373-3377

Nichols NN, Dien BS, Guisado GM, López MJ (2005) Bioabatement to remove inhibitors from biomassderived sugar hydrolysates. Appl Biochem Biotechnol 121:379-390

Nigam JN (2001) Ethanol production from wheat straw hemicellulose hydrolysate by Pichia stipitis. J Biotechnol 87:17-27

Nilsson A, Modig T, Gorwa-Grauslund MF, HahnHägerdal B, Lidén G (2005) Furan reduction capacity of Saccharomyces cerevisiae strains in fermentation of dilute-acid hydrolysates. J Biotechnol Abstracts 118S1:S1-S189

Nissen TL, Anderlund M, Nielsen J, Villadsen J, KiellandBrandt MC (2001) Expression of a cytoplasmic transhydrogenase in Saccharomyces cerevisiae results in formation of 2-oxoglutarate due to depletion of the NADPH pool. Yeast 18:19-32

Nissen TL, Hamann CW, Kielland-Brandt MC, Nielsen J, Villadsen J (2000) Anaerobic and aerobic batch cultivations of Saccharomyces cerevisiae mutants impaired in glycerol synthesis. Yeast 16:463-474

Oh D, Hopper JE (1990) Transcription of a yeast phosphoglucomutase isozyme gene is galactose inducible and glucose repressible. Mol Cell Biol 10:1415-1422

Oosterveld A (1997) Thesis: Pectic substances from sugar beet pulp: structural features, enzymatic modification, and gel formation. Wageningen Universiteit

Ostergaard S, Walloe KO, Gomes SG, Olsson L, Nielsen J (2001) The impact of GAL6, GAL80, and MIG1 on glucose control of the GAL system in Saccharomyces cerevisiae. FEMS Yeast Res 1:47-55

Palmqvist E, Grage H, Meinander NQ, Hahn-Hägerdal B (1999) Main and interaction effects of acetic acid, furfural, and para-hydroxybenzoic acid on growth and ethanol productivity of yeasts. Biotechnol Bioeng 63:46-55

Palmqvist E, Hahn-Hägerdal B (2000) Fermentation of lignocellulosic hydrolysates. II: inhibitors and mechanisms of inhibition. Bioresour Technol 74:25-33

Palmqvist E, Hahn-Hägerdal B, Szengyel Z, Zacchi G, Rèczey K (1997) Simultaneous detoxification and enzyme production of hemicellulose hydrolysates 
obtained after steam pretreatment. Enzyme Microb Technol 20:286-293

Pampulha ME, Loureiro-Dias MC (1989) Combined effect of acetic acid, $\mathrm{pH}$ and ethanol on intracellular $\mathrm{pH}$ of fermenting yeast. Appl Microbiol Biotechnol 31:547550

Pampulha ME, Loureiro-Dias MC (1990) Activity of glycolytic enzymes of Saccharomyces cerevisiae in the presence of acetic acid. Appl Microbiol Biotechnol 34:375-380

Perez J, Munoz-Dorado J, de la Rubia T, Martinez J (2002) Biodegradation and biological treatments of cellulose, hemicellulose and lignin: an overview. Int Microbiol 5:53-63

Petschacher B, Leitgeb S, Kavanagh KL, Wilson DK, Nidetzky B (2005). The coenzyme specificity of Candida tenuis xylose reductase (AKR2B5) explored by site-directed mutagenesis and X-ray crystallography. Biochem J 385:75-83

Platt A, Reece RJ (1998) The yeast galactose genetic switch is mediated by the formation of a Gal4pGal80p-Gal3p complex. EMBO J 17:4086-4091

Radoi F, Kishida M, Kawasaki H (2005) Characteristics of wines made by Saccharomyces mutants which produce a polygalacturonase under wine-making conditions. Biosci Biotechnol Biochem 69:2224-2226

Reifenberger E, Boles E, Ciriacy M (1997) Kinetic characterization of individual hexose transporters of Saccharomyces cerevisiae and their relation to the triggering mechanisms of glucose repression. Eur J Biochem 245:324-333

Richard P, Putkonen M, Väänänen R, Londesborough J, Penttilä M (2002) The missing link in the fungal L-arabinose catabolic pathway, identification of the L-xylulose reductase gene. Biochemistry 41:6432-6437

Richard P, Verho R, Putkonen M, Londesborough J, Penttilä M (2003) Production of ethanol from L-arabinose by Saccharomyces cerevisiae containing a fungal L-arabinose pathway. FEMS Yeast Res 3:185-189

Rigo LU, Marechal LR, Vieira MM, Veiga LA (1985) Oxidative pathway for L-rhamnose degradation in Pullularia pullulans. Can J Microbiol 31:817-822

Rizzi M, Erlemann P, Buithanh NA and Dellweg H (1988) Xylose fermentation by yeasts. 4. Purification and kinetic-studies of xylose reductase from Pichia stipitis. Appl Microbiol Biotechnol 29:148-154

Ronnow B, Olsson L, Nielsen J, Mikkelsen JD (1999) Derepression of galactose metabolism in melibiase producing bakers' and distillers' yeast. J Biotechnol 72:213-228

Russell JB (1992) Another explanation for the toxicity of fermentation acids at low $\mathrm{pH}$ : anion accumulation versus uncoupling. J Appl Bacteriol 73:363-370

Sarthy AV, McConaughy BL, Lobo Z, Sundstrom JA, Furlong CE Hall BD (1987) Expression of the Escherichia coli xylose isomerase gene in Saccharomyces cerevisiae. Appl Environ Microbiol 53:1996-2000

Sauer U (2001) Evolutionary engineering of industrially important microbial phenotypes. Adv Biochem Eng Biotechnol 73:129-169
Sawada H, Takagi Y (1964) The metabolism of L-rhamnose in Escherichia coli III L-rhamnulose-phosphate aldolase. Biochim Biophys Acta 92:26-32

Schloss PD, Handelsman J (2003) Biotechnological prospects from metagenomics. Curr Opin Biotechnol 14:303-310

Sedlak M, Ho NWY (2001) Expression of E. coli araBAD operon encoding enzymes for metabolizing L-arabinose in Saccharomyces cerevisiae. Enzyme Microb Technol 28:16-24

Sedlak M, Ho NWY (2004) Production of ethanol from cellulosic biomass hydrolysates using genetically engineered Saccharomyces yeast capable of cofermenting glucose and xylose. Appl Biochem Biotechnol 114:403-416

Serrat M, Bermúdez RC, Villa TG (2004) Polygalacturonase and ethanol production in Kluyveromyces marxianus: potential use of polygalacturonase in foodstuffs. Appl Biochem Biotechnol 117:49-64

Sirotek K, Slováková L, Kopecný J, Marounek M (2004) Fermentation of pectin and glucose, and activity of pectin-degrading enzymes in the rabbit caecal bacterium Bacteroides caccae. Lett Appl Microbiol 38:327-332

Sjöström E (1991) Carbohydrate degradation products from alkaline treatment of biomass. Biomass Bioenergy 1:61-64

Slininger PJ, Bothast RJ, Vancauwenberge JE, Kurtzman CP (1982) Conversion of D-xylose to ethanol by the yeast Pachysolen tannophilus. Biotechnol Bioeng 24:371-384

Sonderegger M, Jeppsson M, Larsson C, Gorwa-Grauslund MF, Boles E, Olsson L, Spencer-Martins I, HahnHägerdal B, Sauer U (2004) Fermentation performance of engineered and evolved xylose-fermenting Saccharomyces cerevisiae strains. Biotechnol Bioeng 87:90-98

Sonderegger M, Sauer U (2003) Evolutionary engineering of Saccharomyces cerevisiae for anaerobic growth on xylose. Appl Environ Microbiol 69:1990-1998

Taherzadeh MJ, Gustafsson L, Niklasson C, Lidén G (1999) Conversion of furfural in aerobic and anaerobic batch fermentation of glucose by Saccharomyces cerevisiae. J Biosci Bioeng 87:169-174

Taherzadeh MJ, Gustafsson L, Niklasson C, Lidén G (2000) Physiological effects of 5-hydroxymethylfurfural on Saccharomyces cerevisiae. Appl Microbiol Biotechnol 53:701-708

Taherzadeh MJ, Niklasson C, Lidén G, Eklund R, Gustafsson L (1997) Characterization and fermentation of dilute-acid hydrolyzates from wood. Ind Eng Chem Res 36:4659-4665

Takagi Y, Sawada H (1964a) The metabolism of L-rhamnose in Escherichia coli I. L-rhamnose isomerase. Biochim Biophys Acta 92:10-17

Takagi Y, Sawada H (1964b) The metabolism of L-rhamnose in Escherichia coli II L-rhamnulose kinase. Biochim Biophys Acta 92:18-25

Thakur BR, Singh RK, Handa AK (1997) Chemistry and uses of pectin - a review. Crit Rev Food Sci Nutr $37: 47-73$ 
Thomas KC, Hynes SH, Ingledew WM (2001) Effect of lactobacilli on yeast growth, viability and batch and semi-continuous alcoholic fermentation of corn mash. J Appl Microbiol 90:819-828

Toivari MH, Aristidou A, Ruohonen L, Penttilä M (2001) Conversion of xylose to ethanol by recombinant Saccharomyces cerevisiae: importance of xylulokinase (XKS1) and oxygen availability. Metab Eng 3:236-249

Toivola A, Yarrow D, Van den Bosch E, van Dijken JP, Scheffers WA (1984) Ethanolic fermentation of D-xylose by yeasts. Appl Environ Microbiol 47:1221-1223

Twerdochlib AL, Pedrosa FO, Funayama S, Rigo LU (1994) L-rhamnose metabolism in Pichia stipitis and Debaryomyces polymorphus. Can J Microbiol 40:896902

van Dijken JP, Scheffers WA (1986) Redox balances in the metabolism of sugars by yeasts. FEMS Microbiol Rev 32:199-224

van Rooyen R, Hahn-Hägerdal B, La Grange DC, van Zyl WH (2005) Construction of cellobiose-growing and fermenting Saccharomyces cerevisiae strains. J Biotechnol 120:284-295

Verduyn C, Postma E, Scheffers WA, van Dijken JP (1990a) Energetics of Saccharomyces cerevisiae in anaerobic glucose-limited chemostat cultures. J Gen Microbiol 136:405-412

Verduyn C, Postma E, Scheffers WA, van Dijken JP (1990b) Physiology of Saccharomyces cerevisiae in anaerobic glucose-limited chemostat cultures. J Gen Microbiol 136:395-403

Verduyn C, Postma E, Scheffers WA, van Dijken JP (1992) Effect of benzoic acid on metabolic fluxes in yeasts: a continuous-culture study on the regulation of respiration and alcoholic fermentation. Yeast 8:501-517

Verho R, Londesborough J, Penttilä M, Richard P (2003) Engineering redox cofactor regeneration for improved pentose fermentation in Saccharomyces cerevisiae. Appl Environ Microbiol 69:5892-5897

Verho R, Putkonen M, Londesborough J, Penttilä M, Richard P (2004) A novel NADH-linked L-xylulose reductase in the L-arabinose catabolic pathway of yeast. J Biol Chem 279:14746-14751

Vincent SF, Bell PJ, Bissinger P, Nevalainen KM (1999) Comparison of melibiose utilizing baker's yeast strains produced by genetic engineering and classical breeding. Lett Appl Microbiol 28:148-152

Visser J, Van Rooijen R, Dijkema C, Swart K, Sealy-Lewis HM (1988) Glycerol uptake mutants of the hyphal fungus Aspergillus nidulans. J Gen Microbiol 134:655659

Visser W, Scheffers WA, Batenburg-van der Vegte WH, van Dijken JP (1990) Oxygen requirements of yeasts. Appl Environ Microbiol 56:3785-3792
Wahlbom CF, Hahn-Hägerdal B (2002) Furfural, 5-hydroxymethyl furfural, and acetoin act as external electron acceptors during anaerobic fermentation of xylose in recombinant Saccharomyces cerevisiae. Biotechnol Bioeng 78:172-178

Walfridsson M, Bao X, Anderlund M, Lilius G, Bulow L, Hahn-Hägerdal B (1996) Ethanolic fermentation of xylose with Saccharomyces cerevisiae harboring the Thermus thermophilus xylA gene, which expresses an active xylose (glucose) isomerase. Appl Environ Microbiol 62:4648-4651

Walfridsson M, Hallborn J, Penttilä M, Keränen S, HahnHägerdal B (1995) Xylose-metabolizing Saccharomyces cerevisiae strains overexpressing the TKL1 and $T A L 1$ genes encoding the pentose phosphate pathway enzymes transketolase and transaldolase. Appl Environ Microbiol 61:4184-4190

Wang PY, Schneider H (1980) Growth of yeasts on D-xylulose. Can J Microbiol 26:1165-1168

Wilson DM, Ajl S (1955) The metabolism of L-rhamnose by Escherichia coli. Biochim Biophys Acta 17:289

Wilson DM, Ajl S (1957a) Metabolism of L-rhamnose by Escherichia coli. I. L-rhamnose isomerase. J Bacteriol 73:410-414

Wilson DM, Ajl S (1957b) Metabolism of L-rhamnose by Escherichia coli. II. The phosphorylation of L-rhamnulose. J Bacteriol 73:415-420

Witteveen CFB, Busink R, Vandevondervoort P, Dijkema C, Swart K, Visser J (1989) L-arabinose and D-xylose catabolism in Aspergillus niger. J Gen Microbiol 135:2163-2171

Witteveen CFB, Weber F, Busink R, Visser J (1994) Isolation and characterization of two xylitol dehydrogenases from Aspergillus niger. Microbiology 140:1679-1685

Wu YB, Reece RJ, Ptashne M (1996) Quantitation of putative activator-target affinities predicts transcriptional activating potentials. EMBO J 15:3951-3963

Yoon SH, Mukerjea R, Robyt JF (2003) Specificity of yeast (Saccharomyces cerevisiae) in removing carbohydrates by fermentation. Carbohydr Res 338:1127-1132

Zaldivar J, Nielsen J, Olsson L (2001) Fuel ethanol production from lignocellulose: a challenge for metabolic engineering and process integration. Appl Microbiol Biotechnol 56:17-34

Zandleven J, Beldman G, Bosveld M, Benen J, Voragen A (2005) Mode of action of xylogalacturonan hydrolase towards xylogalacturonan and xylogalacturonan oligosaccharides. Biochem J 387:719-725 